\title{
Criptógamos do Parque Estadual das Fontes do Ipiranga, São Paulo, SP. Algas, 25: Bacillariophyceae (Naviculales: Pinnulariaceae)
}

\author{
Angélica Cristina Righetti da Rocha ${ }^{1,3}$ e Carlos Eduardo de Mattos Bicudo ${ }^{2}$
}

Recebido: 30.05.2008; aceito: 30.10.2008

\begin{abstract}
Cryptogams of the "Parque Estadual das Fontes do Ipiranga", São Paulo, SP. Algae, 25: Bacillariophyceae (Naviculales: Pinnulariaceae)). Taxonomic survey of representatives of family Pinnulariaceae (Naviculales, Bacillariophyceae) in the Parque Estadual das Fontes do Ipiranga, São Paulo, Brazil. Two genera (Caloneis with 1 and Pinnularia with 12 species) and 20 taxa altogether, including 13 species and seven varieties that are not the typical of their respective species were identified. One variety, Pinnularia brauniana (Grunow) Mills var. sanctipaulensis Rocha, is described as new to science. Pinnularia brauniana (Grunow) Mills var. sanctipaulensis Rocha and P. subgibba Krammer var. lanceolata Gaiser \& Johanser are the best geographically represented species in the Parque area occurring in 5 localities, whereas and Caloneis hyalina Hustedt, Pinnularia biceps Gregory var. biceps, $P$. grunowii Krammer, P. joculata (Manguin) Krammer, $P$. schoenfelderi Krammer, $P$. subanglica Krammer, $P$. tabellaria Ehrenberg and $P$. viridis (Nitzsch) Ehrenberg var. viridis are the least represented ones, been found in a single locality each.
\end{abstract}

Key words: Brazil, Caloneis, Pinnularia

RESUMO - (Criptógamos do Parque Estadual das Fontes do Ipiranga, São Paulo, SP. Algas. 25: Bacillariophyceae (Naviculales: Pinnulariaceae)). Levantamento dos representantes da família Pinnulariaceae (Naviculales, Bacillariophyceae) do Parque Estadual das Fontes do Ipiranga, São Paulo, Brasil. Foram identificados dois gêneros (Caloneis com 1 e Pinnularia com 12 espécies) e 20 táxons no total, distribuídos em 13 espécies e sete variedades não típicas de suas respectivas espécies. Uma variedade, Pinnularia brauniana (Grunow) Mills var. sanctipaulensis Rocha, é descrita como nova para a ciência. Pinnularia brauniana (Grunow) Mills var. sanctipaulensis Rocha e P. subgibba Krammer var. lanceolata Gaiser \& Johanser são, geograficamente, as espécies mais bem distribuídas no PEFI por ocorrerem em 5 localidades cada; e Caloneis hyalina Hustedt, Pinnularia biceps Gregory var. biceps, $P$. grunowii Krammer, $P$. joculata (Manguin) Krammer, $P$. schoenfelderi Krammer, $P$. subanglica Krammer, $P$. tabellaria Ehrenberg e $P$. viridis (Nitzsch) Ehrenberg var. viridis as menos bem representadas, por ocorrerem em uma localidade apenas cada uma.

Palavras-chave: Brasil, Caloneis, Pinnularia

\section{Introdução}

Dos cinco gêneros classificados na família Pinnulariaceae (Caloneis Cleve, Diatomella Greville, Dimidiata Hajós, Oestrupia Heiden ex Hustedt e Pinnularia Ehrenberg, nom. cons.), apenas o último já havia sido documentado para o PEFI, Parque Estadual das Fontes do Ipiranga. A maioria dos documentos a este respeito consta, entretanto, de trabalhos de cunho ecológico, onde as referências são feitas só nas listas dos táxons identificados, sem serem acompanhadas de descrição e/ou ilustração.

Moura (1997) apenas referiu a presença do gênero Pinnularia no PEFI, ao analizar a estrutura e a produção primária nos períodos de chuva e seca, da comunidade perifítica no Lago das Ninféias durante o processo de colonização em substrato artificial. No mesmo ano, Tucci (1997) estudou a variação temporal e espacial da estrutura da comunidade do fitoplâncton do Lago das Garças também nos períodos de chuva e seca e relacionou a ocorrência, embora considerada rara, de Pinnularia cf. borealis Ehrenberg nos dois períodos. Parte deste estudo foi publicada por Sant'Anna et al. (1997) onde, de novo, é citada a presença de $P$. cf. borealis Ehrenberg no Lago das Garças.

Em 1999, Lopes listou $P$. divergens W. Smith var. divergens, $P$. maior (Kützing) Rabenhorst var. pulchella Boyer, P. mesogongyla Ehrenberg var. mesogongyla e $P$. viridis (Nitzsch) Ehrenberg ao estudar os efeitos perturbatórios que afetaram a biomassa, a composição e a diversidade de espécies do fitoplâncton do Lago do IAG (Lopes 1999).

1. Universidade Estadual Paulista, Av. 24-A, no 1515, 13506-900 Rio Claro, SP, Brasil

2. Instituto de Botânica, Caixa Postal 3005, 01061-970 São Paulo, SP, Brasil

3. Autor para correspondência: angelica_righetti@yahoo.com.br 
Vercellino (2001) pesquisou a sucessão da comunidade de algas perifíticas nos lagos do IAG e das Garças e fez referência a P. biceps Gregory nos períodos tanto de chuva quanto de seca.

Fernandes (2002) identificou Pinnularia sp. a partir de material dos lagos das Nascentes, dos Bugios e das Ninféias e de uma das nascentes do riacho Ipiranga. Tal trabalho versou sobre educação ambiental e foi realizado utilizando o Jardim Botânico de São Paulo como ambiente.

Durante a avaliação do perifíton como sensor da oligotrofização experimental realizado com material do Lago das Garças, Barcelos (2003) apenas referiu a presença de uma espécie de Pinnularia sem, entretanto, identificá-la.

Ferragut (2004) estudou as respostas das algas perifíticas e planctônicas à manipulação de nitrogênio e fósforo no Lago do IAG e registrou a presença de $P$. biceps Gregory, $P$. divergens Smith var. divergens e $P$. gentilis Donkin no lago.

Mais recentemente, Fermino (2006) listou $P$. gibba e $P$. viridis ao avaliar, sazonalmente, os efeitos do enriquecimento por nitrogênio e fósforo sobre o perifíton do Lago das Ninféias. Fermino (2006) não incluiu os nomes dos autores das duas espécies relacionadas.

Abordando os trabalhos de cunho apenas ou eminentemente taxonômico, Sant'Anna et al. (1989) descreveram, embora muito sucintamente, ilustraram com desenhos feitos com auxílio de câmara-clara e forneceram as medidas de interesse taxonômico de uma espécie de Pinnularia, P. borealis Ehrenberg e de duas outras não identificadas, que nomearam Pinnularia sp. 1 e Pinnularia sp. 2. As prováveis três espécies ocorreram no fitoplâncton do Lago das Garças.

Em síntese, o conhecimento até então sobre as Pinnulariaceae do PEFI vem de trabalhos onde a taxonomia foi feita, principalmente, como meio e não como fim. Inclui, conseqüentemente, pouca informação sobre as espécies, variedades e formas taxonômicas identificadas. Informação relevante sobre a família também não está presente nas publicações de cunho taxonômico. O objetivo do presente trabalho foi conhecer a riqueza taxonômica e a variabilidade, em populações amostradas, das características diacríticas dos táxons infragenéricos da família Pinnulariaceae do PEFI.

\section{Material e métodos}

O material usado na presente pesquisa foi a coleção de amostras constantes do acervo do Herbário
Científico do Estado "Maria Eneyda P. Kauffmann Fidalgo" (SP) do Instituto de Botânica da Secretaria do Meio Ambiente do Estado de São Paulo. Os métodos de coleta, fixação e preservação do material estão descritos em Rocha (2008). A preparação das lâminas semipermanentes para estudo ao microscópio óptico seguiu a técnica de Hasle \& Fryxell (1970) e foi usado Zrax como meio de inclusão (IR = 1,7). Para obtenção das fotomicrografias, foi utilizado um sistema de captura de imagem, com câmara fotográfica digital marca Cânon, modelo G5, no Laboratório de Microscopia da Seção de Ecologia do Instituto de Botânica de São Paulo.

O estudo taxonômico foi baseado, sempre que possível, na análise de populações, com ilustração dos táxons e tomada das medidas do comprimento e da largura e contagem do número de estrias alveoladas em intervalos lineares de $10 \mu \mathrm{m}$. A terminologia utilizada nas descrições e as formas adotadas seguiram Hendey (1964).

\section{Resultados e Discussão}

A família Pinnulariaceae Mann caracteriza-se por ser formada por representantes unicelulares solitários, que raramente formam cadeias curtas. As valvas são lineares a lanceoladas, algumas vezes elípticas, com as extremidades obtusamente arredondadas, podendo ser capitadas a subcapitadas ou levemente alongadas. Os gêneros desta família são comuns e abundantes no plâncton e, principalmente, no perifíton.

Round et al. (1990) incluíram quatro gêneros na família Pinnulariaceae, quais sejam: Diatomella Greville, Dimidiata Hajós, Oestrupia Heiden ex Hustedt e Pinnularia Ehrenberg, nom. cons., que compreendem, no total, 57 espécies. Os referidos autores não concordaram com a identidade separada dos gêneros Pinnularia Ehrenberg e Caloneis Cleve (Round et al. 1990).

Tanto Pinnularia quanto Caloneis possuem estrias do tipo alveolado. Cada estria consiste de uma câmara alongada transapicalmente, que se abre para o exterior através de várias fileiras de pequenos poros (oclusão do tipo hímen) e, para o interior, através de um ou mais forâmens não ocluídos (podem ser pequenos como poros ou amplos e alongados).

Apesar de vários autores concordarem com a sugestão de Round et al. (1990) de unificação dos dois gêneros e a transferência das espécies de Caloneis para Pinnularia, nenhuma proposta formal foi feita até o momento (Brassac \& Ludwig 2006). O próprio Mann 
(2001) afirmou que até se ter uma idéia mais clara das relações taxonômicas dentro da família Pinnulariaceae, especialmente de suas sequiências genéticas, é melhor considerar Caloneis e Pinnularia gêneros separados, em vez de propor algo que não possa ser consolidado. Nesse contexto, optamos no presente trabalho, pela separação tradicional dos dois gêneros e a classificação de ambos na família Pinnulariaceae.

\section{Caloneis Cleve}

Valvas freqüentemente convexas, podendo ser lineares, lanceoladas, panduriformes ou, raro sigmóides e assimétricas; estrias geralmente paralelas e divergentes, raro convergentes no sentido das extremidades valvares e cruzadas por uma ou várias linhas longitudinais (Cleve 1894-1895).

Caloneis hyalina Hustedt, Archiv für Hydrobiologie 15(2): 281, pl. 15, fig. 8-10. 1937.

Figura 1

Valvas lanceoladas, extremidades valvares atenuado-arredondadas, esterno da rafe linear, extremamente estreito, área central retangular, assimétrica, lateralmente expandida, alcançando as margens formando fáscia, rafe filiforme, extremidades proximais sutilmente fletidas no mesmo sentido, estrias alveoladas, inconspícuas, ca. 19,3 $\mu$ m compr., ca. 5,9 $\mu \mathrm{m}$ larg., estrias em $10 \mu \mathrm{m}$ não contadas.
Hábitat: perifíton no Lago dos Bugios (SP284901).

Patrick \& Reimer (1966) comentaram que os espécimes que observaram de $C$. hyalina apresentaram linhas longitudinais em cada margem da valva, fato não observado por Hustdet (1930). Esta característica foi observada com muita dificuldade no único indivíduo encontrado durante o presente estudo. Não foi possível verificar o padrão da rafe distal e as estrias apareceram inconspícuas ao microscópio óptico.

A análise das ilustrações de $C$. hyalina em Simonsen (1987) mostrou variação no que tange ao tamanho da área central desde ampla até estreita. Esta variação também foi observada nos espécimes desta espécie nas várias diatomoflórulas brasileiras.

\section{Pinnularia Ehrenberg}

Gênero característico por ser constituído de indivíduos de hábito solitário, raramente colonial. Os espécimes possuem dois cromoplastídios laminares independentes situados um em frente ao outro, com as margens algumas vezes retalhadas ou os dois plastídios unem-se abaixo da hipovalva por um istmo central formando um único em forma de "H". As valvas podem ser lineares, lanceoladas ou elípticas, com margens retas ou onduladas e extremidades valvares arredondadas, rostradas ou capitadas (Round et al. 1990).

Chave para identificação das espécies e variedades de Pinnularia

1. Presença de espessamento silicoso em cada lado da área central

2. Valvas linear-lanceoladas P. divergens var. divergens

2. Valvas não lineares

3. Extremidades valvares arredondadas a capitadas P. divergens var. malayensis

3. Extremidades valvares subcapitadas P. divergens var. mesoleptiformis

1. Ausência de espessamento silicoso em cada lado da área central

4. Esterno da rafe ornado com granulações

5. Extremidades valvares capitadas P. acrosphaeria var. acrosphaeria

5. Extremidades valvares arredondadas P. acrosphaeria var. tumidula

4. Esterno da rafe sem granulações

6. Margens valvares 3-onduladas

7. Extremidades valvares capitadas P. grunowii

7. Extremidades valvares subcapitadas P. gibba var. subundulata

6. Margens valvares não 3-onduladas

8. Valvas com intumescimento mediano

9. Valvas lineares P. tabellaria

9. Valvas elíptico-lanceoladas $P$. viridiformis var. viridiformis

8. Valvas sem intumescimento mediano 10. Valvas lineares 
11. Extremidades valvares capitadas

12. Fáscia unilateral P. biceps

12. Fáscia bilateral P. subanglica

11. Extremidades valvares não capitadas

13. Extremidades valvares subcapitadas P. subcapitata var. subcapitata

13. Extremidades valvares não subcapitadas P. subgibba var. sublinearis

10. Valvas não lineares

14. Extremidades valvares subcapitadas P. subgibba var. lanceolata

14. Extremidades valvares não subcapitadas

15. Extremidades capitadas

16. Esterno da rafe não formando um espaço amplo com a área central P. mayeri

16. Esterno da rafe formando um espaço amplo com a área central

17. Fáscia longitudinalmente ampla, $\geq 1 / 3$ do comprimento valvar ... P. joculata

17. Fáscia longitudinal, $<1 / 3$ do comprimento valvar

P. brauniana var. sanctipaulensis

15. Extremidades não capitadas

18. Área central formando fáscia P. schoenfelderi

18. Área central não formando fáscia $P$. viridis var. viridis

Pinnularia acrosphaeria W. Smith var. acrosphaeria, Synopsis of British Diatomaceae 1: 58, pl. 19, fig. 183. 1853.

Figuras 40-41

Valvas lineares, intumescidas na região mediana, extremidades valvares capitadas, esterno da rafe linear, amplo, ornado com granulações, área central não diferenciada do esterno, rafe filiforme, extremidades proximais em forma de poros muito pequenos, fletidas no mesmo sentido, extremidades terminais em forma de baioneta, mais fechada em uma das extremidades da valva, mais aberta na outra, estrias alveoladas, paralelas a levemente radiadas para as extremidades, 66-76,9 $\mu$ m compr., 10,8-12,3 um larg., 12-14 estrias alveoladas em $10 \mu \mathrm{m}$.

Hábitat: plâncton no Lago das Garças (SP255752, SP294905) e no Lago das Ninféias (SP294900); perifíton no Lago das Garças (SP290904), no Lago do IAG (SP294906), no Lago do Monjolo (SP294909) e no Lago das Ninféias (SP294899).

Não foram observadas diferenças morfológicas intra nem interpopulacional nas unidades amostrais estudadas de P. acrosphaeria W. Smith var. acrosphaeria.
As extremidades valvares são capitadas e descontínuas do corpo valvar principal, o que confere às valvas a aparência intumescida. A extremidade distal da rafe apresenta a forma de baioneta, não seguindo, porém, o mesmo padrão em cada pólo. É variável, podendo ser mais fechada em um dos pólos, com a forma da letra "C" e no outro, mais aberta, com a forma da letra " $\mathrm{L}$ ".

De acordo com Krammer (2000), grande número de táxons infraespecíficos desta espécie existe em função da variação morfológica do contorno valvar, da forma e ornamentação do esterno da rafe e da área central e da densidade de estrias.

Para Patrick \& Reimer (1966), P. acrosphaeria W. Smith é característica pelo esterno granular e amplo. Os referidos autores afirmaram que Smith deu, em 1853, o nome $P$. acrosphaeria para esta espécie. No mesmo ano, porém alguns meses mais tarde, Rabenhorst transferiu Frustulia acrosphaeria para o gênero Pinnularia, efetuando a combinação P. acrosphaeria (Brébisson) Rabenhorst. Esta não é, porém, a mesma proposta antes por Smith. Com isso, fica claro que outro epíteto específico precisa ser utilizado para nomear os espécimes de Rabenhorst já que, de acordo com o Código Internacional de 

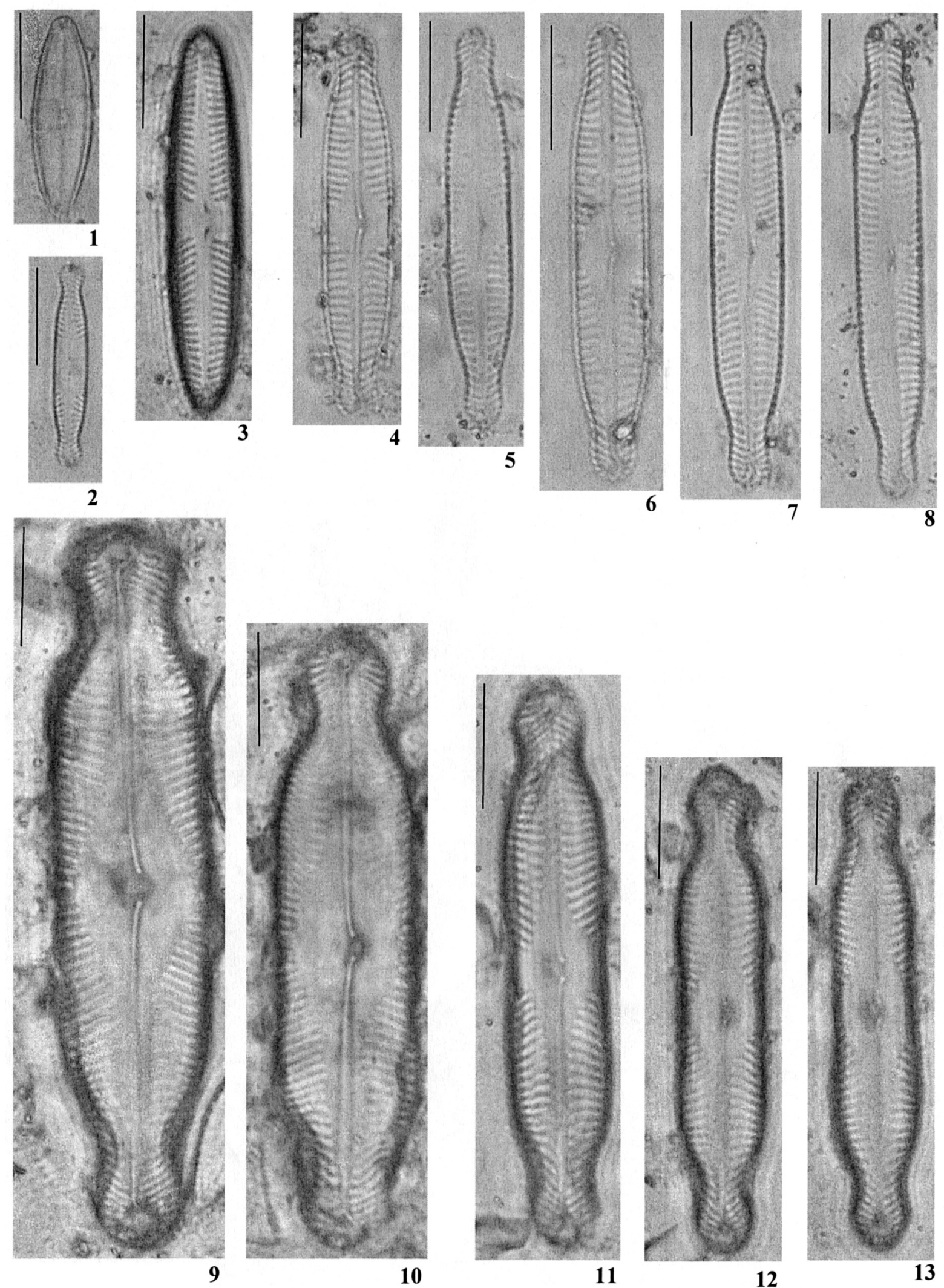

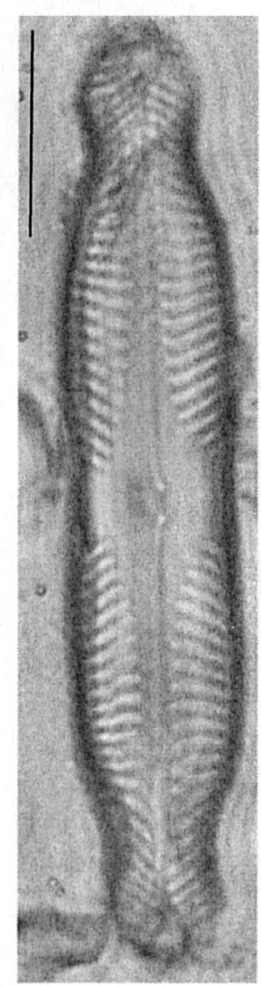

11

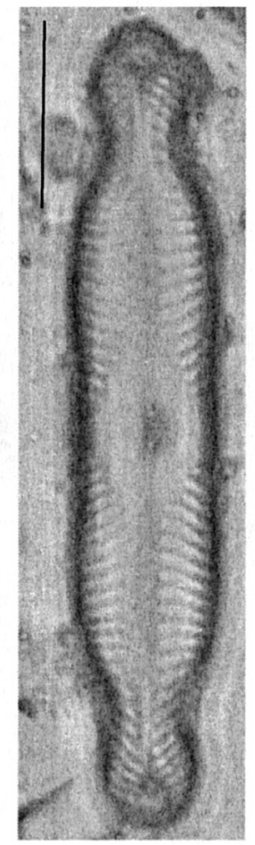

12

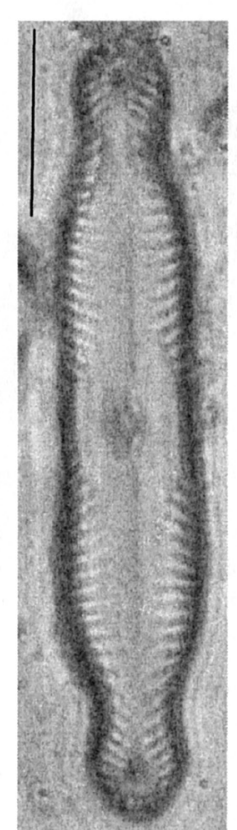

13

Figura 1. Caloneis hyalina. Figura 2. Pinnularia joculata. Figura 3. P. schoenfelderi. Figuras 4-8. P. subcapitata. Figuras 9-10. P. biceps. Figuras 11-13. P. grunowii. Escalas valem $10 \mu \mathrm{m}$. 
Nomenclatura Botânica, não podem coexistir duas combinações absolutamente idênticas identificando materiais distintos. Krammer (2000) confirmou as observações em Patrick \& Reimer (1966) e acrescentou que a espécie de Rabenhorst possui esterno estreito. Com isso, os espécimes de Rabenhorst são mais semelhantes aos encontrados por Brébisson.

Ao analisar P. acrosphaeria em Rabenhorst (1853: pl. 6, fig. 36), nota-se que se trata de uma espécie diferente. A ilustração representa um espécime mais afilado, alongado, com o esterno da rafe bem estreito, a área central pequena e circular e as estrias paralelas em toda a valva. Hustedt (1930), Germain (1981) e Krammer \& Lange-Bertalot (1986), entre outros autores, atribuíram a autoria do binômio específico, indistintamente, a Brébisson ou a Rabenhorst. A análise das ilustrações e das características antes mencionadas para separar o material de Rabenhorst do de Smith demonstrou que todas se referem a $P$. acrosphaeria W. Smith.

Krammer (1992a) propôs uma nova espécie, $P$. gibbiformis Krammer, incluíndo entre outros sinônimos, Frustulia acrosphaeria Brébisson, Navicula acrosphaeria Kützing e P. acrosphaeria (Brébisson) Rabenhorst.

Pinnularia acrosphaeria W. Smith var. tumidula Krammer in Lange-Bertalot, Diatoms of Europe 1: 55, pl. 21, fig. 8-9. 2000.

Figuras 42-44

Valvas lineares, intumescidas na região mediana, extremidades valvares arredondadas, esterno da rafe linear, amplo, ornado com granulações, área central não diferenciada do esterno, rafe filiforme, extremidades proximais em forma de poros muito pequenos, fletidas no mesmo sentido, extremidades terminais em forma de baioneta, mais fechada em uma das extremidades da valva, mais aberta na outra, estrias alveoladas, paralelas a levemente radiadas para as extremidades, 72,7-91,7 $\mu \mathrm{m}$ compr., 11,9-13,2 $\mu \mathrm{m}$ larg., 11-13 estrias alveoladas em $10 \mu \mathrm{m}$.

Hábitat: perifíton no Lago dos Bugios (SP255747), no Lago das Garças (SP294904) e no Lago das Ninféias (SP255743).

Pinnularia acrosphaeria W. Smith var. tumidula Krammer difere da variedade-tipo da espécie, principalmente, pelas valvas lineares e paralelas entre si e pelas extremidades arredondadas e contínuas ao corpo valvar.
A presente população da var. tumidula Krammer coletada no PEFI não apresentou variação morfológica intra ou interpopulacional.

Os indivíduos representantes da var. tumidula Krammer poderiam ser melhor considerados expressões morfológicas da variedade típica da espécie, que seriam distintas entre si e da típica apenas pelas diferentes extremidades valvares. No Lago das Garças, foram encontrados representantes da variedade típica e da não-típica, porém, sem formarem um contínuo de variação da forma das extremidades valvares.

Esta variedade foi originalmente descrita por Krammer (2000) e caracterizada pelo intumescimento mediano das valvas e pelas extremidades arredondadas ou levemente dilatadas. Antes de propor a nova variedade, Krammer (1992a) interpretou os exemplares estudados como morfotipos (morfotipos 2 e 3 ) de $P$. acrosphaeria W. Smith var. acrosphaeria, os quais utilizou mais tarde para propor a atual var. tumidula Krammer.

Pinnularia biceps Gregory var. biceps, Quarterly Journal of Microscopical Science 1856: 8, pl. 4, fig. 1 (28). 1856.

Figuras 9-10

Valvas lineares, extremidades valvares capitadas, esterno da rafe linear, pouco expandido, alargando para a área central, área central romboidal, ampla, lateralmente expandida em uma das margens, formando fáscia estreita, estrias contínuas na outra margem, rafe filiforme, extremidades proximais fletidas no mesmo sentido, extremidades terminais em forma de gancho, estrias alveoladas, radiadas a convergentes para as extremidades, 53,6-61,6 $\mu \mathrm{m}$ compr., 10,3-13,4 $\mu \mathrm{m}$ larg., 11-12 estrias alveoladas em $10 \mu \mathrm{m}$.

Hábitat: perifíton no Lago dos Bugios (SP294901).

A população de $P$. biceps Gregory var. biceps não apresentou qualquer variação morfológica intrapopulacional.

As estrias dos espécimes foram contínuas em uma margem e logo interrompidas na outra, dando origem a uma fáscia unilateral estreita.

Para Krammer (2000) é comum a presença de uma ou mais estrias marginais na região central da valva, podendo também estar ausentes em uma ou em ambas as margens. Os espécimes com fáscia ampla são mais raros. Entre os vários sinônimos relacionados em Krammer (2000) para P. biceps Gregory var. biceps 
consta P. mesolepta morfotipo 1 (Krammer 1992a: pl. 43, fig. 1-4), que inclui espécimes com fáscia.

A população do Lago dos Bugios foi idêntica à da Bolívia examinada por Morales \& Vis (2007). Destaque deve ser dado à ampla área central desses indivíduos. A população descrita em Morales \& Vis (2007) apresentou uma pequena variação morfológica em relação à fáscia, que se apresentou estendida uni ou bilateralmente.

De acordo com Patrick \& Reimer (1966), Smith considerou, em 1856, P. interrupta W. Smith 1853 constituída por exemplares com fáscia. Assim como Gregory fez, em 1856, Patrick \& Reimer (1966) detectaram também em $P$. biceps um contínuo de variação entre tais extremos.

Muitas obras consideram P. biceps Gregory e $P$. interrupta W. Smith sinônimos heterotípicos (taxonômicos), porém, variam quanto a qual epíteto deve prevalecer. Patrick \& Reimer (1966) afirmaram que Smith considerou incorreto o uso do epíteto biceps, pois $P$. biceps Gregory 1856 não é a mesma coisa que Navicula biceps Ehrenberg 1841. Esta última espécie pertence, hoje, ao gênero Anomoeoneis Pfitzer.

Conforme Krammer (2000), W. Smith baseouse, em 1853, em Stauroneis parva (Ehrenberg) Kützing para propor $P$. interrupta e esta última espécie é diferente do complexo interrupta/biceps por apresentar exemplares de tamanho menor e contorno valvar diferente. Dessa maneira, para Ross em 1947 (veja Krammer 2000), a combinação P. biceps de Gregory teria prioridade sobre $P$. interrupta W. Smith. O Código Internacional de Nomenclatura Botânica aceita o uso, em uma combinação diferente, de epítetos que tenham sido antes considerados supérfluos (art. 58.1). Desta forma, o nome $P$. biceps de Gregory é válido segundo o referido Código, sendo $P$. interrupta W. Smith seu sinônimo heterotípico.

Muitos espécimes de P. biceps Gregory var. biceps representados na literatura especializada apresentam as margens 3-onduladas. Tais espécimes diferem de P. biceps Gregory var. gibberula (Hustedt) Krammer porque, nesta, a ondulação central da margem valvar é mais evidente do que as distais ou as margens podem carecer de ondulações, porém, são convexas.

Pinnularia anglica Krammer lembra, morfologicamente, P. biceps Gregory. Krammer (2000) comentou que a primeira foi identificada, entre outras possibilidades, com $P$. interrupta $\mathrm{W}$. Smith, $P$. biceps Gregory e P. microstauron (Ehrenberg) Cleve. Ilustrações do morfotipo 1 de $P$. anglica Krammer em Krammer (2000) mostram espécimes com fáscia bem estreita, às vezes ausente, ou com estrias quase completamente marginais em uma ou em ambas as margens. Esses espécimes são muito parecidos com exemplares de $P$. biceps Gregory da literatura e do presente estudo. Porém, em $P$. anglica Krammer as extremidades valvares são bem mais estreitas em relação ao corpo valvar e são sub-rostradas.

Pinnularia brauniana (Grunow) Mills var. sanctipaulensis Rocha, var. nov.

Figuras 21-25

A varietate typica ambitu valvari linearilanceolato, valvis angustioribus et elongatis et externo ampliori differt.

Typus: BRASIL. São Paulo: São Paulo, Parque Estadual das Fontes do Ipiranga, Lago das Nimféias, plancton, D.C. Bicudo, T.A.V. Ludwig \& D.M. Figueiredo s.n., 18-VII-1991 (SP255743).

Difere da variedade típica da espécie por apresentar o contorno valvar linear-lanceolado, as valvas mais estreitas e alongadas e esterno mais amplo.

Valvas linear-lanceoladas, extremidades valvares capitadas, esterno da rafe formando um espaço lanceolado com a área central, amplo, área central lateralmente expandida, alcançando as margens, formando fáscia, rafe filiforme, extremidades proximais em forma de pequenos poros, fletidos no mesmo sentido, extremidades terminais em forma de gancho, estrias alveoladas, radiadas, convergentes para as extremidades, 42,5-57,7 $\mu \mathrm{m}$ compr., 7,3-9,5 $\mu \mathrm{m}$ larg., 10-12 estrias alveoladas em $10 \mu \mathrm{m}$.

Hábitat: plâncton no hidrofitotério (SP255746), no córrego Pirarungaua (SP255750), no Lago dos Bugios (SP255748), no Lago do IAG (SP294908) e no Lago das Ninféias (SP255744, SP294900); perifíton no córrego Pirarungaua (SP255749), no Lago dos Bugios (SP255747), no Lago do IAG (SP294906), no Lago das Garças (SP255751), no Lago do Monjolo (SP294909) e no Lago das Ninféias (SP255743, SP294899).

Os espécimes presentemente examinados não apresentaram variação intra nem interpopulacional.

As populações atualmente estudadas são muito semelhantes às demais identificadas para o Brasil, porém, com as identificadas com $P$. brauniana (Grunow) Mills var. brauniana. Quando se observam as obras mais antigas e clássicas para identificação do presente material como, por exemplo, os trabalhos de Schmidt (1876: pl. 45, fig. 77-78) e van Heurck 
(1880-1881, pl. 6, fig. 21), respectivamente, para Navicula brauniana Grunow e N. braunii Grunow, nota-se, avaliada toda a informação contida naqueles trabalhos, uma pequena variação nas valvas, que são lanceoladas e amplas. Os presentes espécimes do PEFI possuem valvas linear-lanceoladas, porém, mais estreitas e mais alongadas.

Metzeltin \& Lange-Bertalot (2002: pl. 84, fig. 1014) apresentaram dois morfotipos, um dos quais pode ser considerado representante desta nova variedade. O primeiro deles representa, de fato, $P$. brauniana (Grunow) Mills, de acordo com os trabalhos mais antigos anteriormente citados, enquanto o segundo é idêntico àquele do presente trabalho. Os mesmos autores acima comentaram ainda que ambos os morfotipos foram coletados de ambientes diferentes e representam, possivelmente, táxons diferentes.

Pinnularia subanglica Krammer é distinta de P. brauniana (Grunow) Mills var. sanctipaulensis Rocha por apresentar valvas lineares, muito levemente convexas, e extremidades menos alongadas. Para Krammer (2000), contorno valvar, tamanho da valva, esterno e área central caracterizam $P$. subanglica Krammer. Finalmente, $P$. rumrichae Krammer possui certa semelhança com os espécimes da nova variedade em tela. Porém, em $P$. rumrichae Krammer, as valvas são lineares, com as margens retas e paralelas e a fáscia bem ampla.

Pinnularia divergens W. Smith var. divergens, Synopsis of British Diatomaceae 1: 57, pl. 18, fig. 177. 1853.

Figuras 29-30

Valvas linear-lanceoladas, levemente onduladas, extremidades valvares sub-rostradas, esterno da rafe linear, estreito, área central romboidal, lateralmente expandida, alcançando as margens, formando fáscia, ornada com espessamento silíceo em cada margem, rafe filiforme, extremidades proximais levemente dilatadas, sutilmente fletidas no mesmo sentido, extremidades terminais em forma de baioneta, estrias alveoladas, fortemente radiadas, convergentes para as extremidades, 44,3-94,3 $\mu$ m compr., 8,5-16,1 $\mu \mathrm{m}$ larg., 11-13 estrias alveoladas em $10 \mu \mathrm{m}$.

Hábitat: plâncton no Lago das Garças (SP255752); perifíton no Lago dos Bugios (SP294901) e no Lago das Ninféias (SP255743); e perifíton/metafíton no brejo do Lago do IAG (SP294908).

As populações examinadas não apresentaram variação morfológica intra ou interpopulacional.
De acordo com Krammer (2000), há atualmente mais de 30 táxons infraespecíficos de $P$. divergens W. Smith descritos na literatura mundial. No entanto, alguns deles devem ser nada mais do que representantes de diferentes estágios do ciclo-de-vida de indivíduos do chamado complexo divergens.

Krammer (2000) propôs $P$. divergens W. Smith var media e a diferenciou da variedade típica da espécie pelo tamanho do eixo apical que é maior nos exemplares da variedade-tipo. A observação das ilustrações das duas variedades em Krammer (2000) mostrou que a diferença entre ambas vai além das medidas. Os representantes da var. media Krammer possuem valva linear, a área central não forma uma fáscia em alguns casos e o espessamento silicoso jamais existe.

Para Patrick \& Reimer (1966), esta espécie é caracterizada pelo espessamento silíceo da área central em cada margem valvar. Porém, nem sempre tal espessamento é visível.

Pinnularia divergens W. Smith var. malayensis Hustedt, Internationale Revue der gesamten Hydrobiologie und Hydrographie 42: 82, fig. 159. 1942.

Figuras 38-39

Valvas lineares, margens retas, intumescidas na região mediana até levemente 3-onduladas, ondulação central mais evidente, distais bastante suaves, extremidades valvares arredondadas a capitadas, esterno da rafe linear, amplo, área central romboidal, lateralmente expandida, alcançando as margens, formando fáscia estreita, ornada com espessamento silíceo em cada margem, rafe complexa, extremidades proximais pouco dilatadas, levemente fletidas no mesmo sentido, extremidades terminais em forma de baioneta, estrias alveoladas, radiadas, levemente convergentes para as extremidades, 88,9-155,8 $\mu \mathrm{m}$ compr., 22,8-26 um larg., 8-10 estrias alveoladas em 10 um.

Hábitat: perifíton no Lago do Monjolo (SP294909); perifíton/metafíton no brejo do Lago do IAG (SP294908).

As populações coletadas no PEFI apresentaram morfotipos diferentes. O primeiro deles é dos espécimes do Lago do Monjolo (fig. 39) e o segundo daqueles do brejo do Lago do IAG (fig. 38). O primeiro morfotipo apresentou valvas com margens retas, apenas um intumescimento mediano, extremidades capitadas (aparência de intumescidas), medidas de 
123,8-155,8 um compr., 22,9-24,8 $\mu \mathrm{m}$ larg. e ca. 8 estrias alveoladas em $10 \mu \mathrm{m}$. Esses exemplares estão totalmente de acordo com a ilustração constante na obra "princeps" de $P$. divergens W. Smith var. malayensis Hustedt. Espécimes muito semelhantes a estes foram identificados por Bigunas (2005) e Metzeltin \& Lange-Bertalot (1998). Frenguelli (1933: pl. 2, fig. 7) ilustrou um indivíduo muito parecido com os anteriormente citados e que identificou com $P$. hartleyana Greville. Ao analisar o holótipo (Metzeltin \& Lange-Bertalot 2002: pl. 83, fig. 1) desta última espécie, notou-se que o mesmo apresenta extremidades arredondadas, embora menos expressivas, o eixo apical relativamente mais longo e o transapical mais estreito, ao contrário do exemplar em Frenguelli (1933), em que as extremidades são bem destacadas do corpo valvar e o eixo apical parece menos alongado. Assim, a identificação de Frenguelli (1933) tende mais para $P$. divergens Smith var. malayensis Hustedt. Em relação ao segundo morfotipo, as valvas apresentaram margens onduladas, sendo as ondulações distais pouco nítidas e a central mais evidente, as extremidades são arredondadas, a amplitude métrica é de 88,9128,22 um compr., 22,9-26 um larg. e ocorrem 9-10 estrias alveoladas em $10 \mu \mathrm{m}$. Metzeltin et al. (2005) documentaram para o Uruguai espécimes muito semelhantes a este morfotipo.

Ao observar as ilustrações do holótipo (Simonsen 1987: pl. 414, fig. 1) e do isótipo (Simonsen 1987: pl. 414, fig. 2) de P. divergens W. Smith var. malayensis Hustedt, percebe-se que ambas mostram indivíduos com margens desde evidentemente até levemente 3-onduladas, sendo a ondulação central mais destacada do que as demais, e extremidades arredondadas a capitadas. O segundo morfotipo é semelhante aos espécimes registrados por Simonsen (1987). A característica "valvas 3-onduladas" destacada por Simonsen (1987) pode ser uma variação morfológica intrapopulacional visto que o isótipo (Simonsen 1987: pl. 414, fig. 2) é levemente 3-ondulado, com as ondulações distais quase imperceptíveis. Este segundo morfotipo pode ser grosseiramente confundido com $P$. divergens $\mathrm{W}$. Smith e suas demais variedades. Porém, a variedade-tipo da espécie é diferente por apresentar valvas linear-lanceoladas a lanceoladas, sem intumescimento mediano, com as extremidades sub-rostradas. Este segundo morfotipo pode também ser confundido com $P$. divergens $W$. Smith var. biconstricta (Cleve-Euler) Cleve-Euler que apresenta, embora ocasionalmente, intumescimentos mediano e distais. Contudo, de acordo com Krammer (2000), as valvas são lineares e as margens comumente paralelas.

Outra variedade que apresenta certa semelhança com $P$. divergens W. Smith var. malayensis Hustedt é $P$. divergens $\mathrm{W}$. Smith var. sublinearis Cleve, que possui valvas linear-elípticas e, em alguns casos, margens onduladas. Mas, não há destaque para a ondulação central e as extremidades são atenuadoarredondadas, bem como, de acordo com Krammer (2000), as dimensões valvares são menores (60-110 $\mu \mathrm{m}$ compr., 13,5-17 $\mu \mathrm{m}$ larg.). Finalmente, a presente variedade guarda certa semelhança com $P$. divergens W. Smith var. undulata (Peragallo \& Héribaud) Hustedt por possui margens valvares trionduladas, porém, as extremidades são subcapitadas a capitadas.

Assim sendo, até que sejam realizados estudos mais aprofundados sobre esta variedade, optamos no presente trabalho por identificar a população do morfotipo 2 com $P$. divergens W. Smith var. malayensis Hustedt.

Pinnularia divergens $\mathrm{W}$. Smith var. mesoleptiformis Krammer \& Metzeltin in Metzeltin \& LangeBertalot, Iconographia Diatomologica 5: 170, pl. 173, fig. 1-4. 1998.

Figuras 27-28

Valvas lineares, 3-onduladas, ondulação mediana mais pronunciada que as demais, extremidades valvares subcapitadas, esterno da rafe linearlanceolado, pouco expandido, área central romboidal, lateralmente expandida, alcançando as margens, formando fáscia estreita, ornada com espessamento silíceo em cada margem, rafe complexa, extremidades proximais levemente dilatadas, fletidas no mesmo sentido, extremidades terminais em forma de baioneta, estrias alveoladas, radiadas, convergentes para as extremidades, 85,7-90,5 $\mu \mathrm{m}$ compr., 12,3-13,1 $\mu \mathrm{m}$ larg., 10-11 estrias alveoladas em $10 \mu \mathrm{m}$.

Hábitat: perifíton no hidrofitotério (SP255745) e no Lago das Garças (SP255751).

Pinnularia divergens $\mathrm{W}$. Smith var. mesoleptiformis Krammer \& Metzeltin difere da variedade-tipo da espécie por apresentar ondulações valvares mais acentuadas, contorno valvar mais linear e extremidades subcapitadas.

Os espécimes identificados das amostras do PEFI não apresentaram variação morfológica intra nem interpopulacional, sendo muito semelhantes às ilustrações originais da var. mesoleptiformis Krammer $\&$ Metzeltin. 
A proposta original de $P$. divergens $\mathrm{W}$. Smith var. mesoleptiformis Krammer \& Metzeltin foi acompanhada por uma descrição em que os autores afirmaram ser muito parecida com $P$. divergens $\mathrm{W}$. Smith var. laticeps Frenguelli, diferindo somente pelas medidas (respectivamente: 69-81 $\mu \mathrm{m}$ compr., 13-14 $\mu \mathrm{m}$ larg., 9-10 estrias em $10 \mu \mathrm{m}$ e 105-120 $\mu \mathrm{m}$ compr., 19-22 um larg., 7-8 estrias em $10 \mu \mathrm{m}$ ).

Ao analisar as ilustrações em Metzeltin \& LangeBertalot (1998) e Frenguelli (1933), respectivamente, de $P$. divergens $W$. Smith var. mesoleptiformis Krammer \& Metzeltin e $P$. divergens W. Smith var. laticeps Frenguelli, percebe-se que, além da variação do comprimento valvar, as duas variedades diferem, notadamente, quanto ao formato das extremidades valvares e ao tipo de rafe. Assim, a var. laticeps Frenguelli possui as extremidades capitadas, no entanto "achatadas", bem como rafe filiforme, enquanto que a var. mesoleptiformis Krammer \& Metzeltin possui as extremidades capitadas e alongadas e a rafe é complexa. As últimas características suportam muito melhor a manutenção da var. mesoleptiformis Krammer \& Metzeltin do que apenas a diferença de medidas.

Metzeltin \& Lange-Bertalot (2002) propuseram uma nova variedade para o complexo divergens: $P$. divergens W. Smith var. madagascariensis Metzeltin. Os referidos autores afirmaram que esta variedade é muito semelhante à var. mesoleptiformis Krammer \& Metzeltin. Mencionaram ainda que as duas variedades em pauta possuem o mesmo tipo de contorno valvar, isto é, linear, ondulado, com as extremidades capitadas a subcapitadas e que as diferenças entre elas seriam, unicamente, as medidas (respectivamente: 82-95 $\mu \mathrm{m}$ compr., 15-16 um larg., 8-11 estrias em $10 \mu \mathrm{m}$ e 69-81 $\mu \mathrm{m}$ compr., 13-14 larg., 9-10 estrias em $10 \mu \mathrm{m}$ ).

Analisando as duas variedades em Metzeltin \& Lange-Bertalot (2002) e Metzeltin \& LangeBertalot (1998), respectivamente, nota-se que a var. mesoleptiformis e a var. madagascariensis são extremamente semelhantes entre si e que as medidas de ambas se sobrepõem. Portanto, optou-se presentemente por identificar a população do PEFI com $P$. divergens $W$. Smith var. mesoleptiformis Krammer \& Metzeltin por este epíteto varietal o mais antigo dos dois e publicado conforme o Código Internacional de Nomenclatura Botânica. O epíteto varietal madagascariensis Metzeltin \& Lange-Bertalot é um seu sinônimo heterotípico (taxonômico).

As medidas do comprimento das valvas no material do PEFI estão de acordo com os valores apresentados por Metzeltin \& Lange-Bertalot (2002) para a var. madagascariensis Metzeltin \& LangeBertalot. As medidas valvares dos representantes da var. mesoleptiformis Krammer \& Metzeltin deverão, no caso da aceitação da presente proposta, ser ampliados de modo a incluir as da var. madagascariensis Metzeltin \& Lange-Bertalot.

Pinnularia gibba Ehrenberg var. subundulata (Mayer ex Hustedt) Frenguelli, Anales del Museo Nacional de Historia Natural 3: 396, pl. 3, fig. 9. 1933 = Pinnularia gibba Ehrenberg var. gibba $\mathrm{f}$. subundulata Mayer ex Hustedt, Süsswasser-Flora Mitteleuropas. 327, fig. 601. 1930.

Figuras 34-36

Valvas lineares, levemente 3-onduladas, extremidades valvares subcapitadas, esterno da rafe linear, estreito, área central rômbica, lateralmente expandida, alcançando as margens, formando fáscia, simétrica ou assimétrica, rafe filiforme, extremidades proximais em forma de poros pequenos, fletidas no mesmo sentido, extremidades terminais em forma de gancho, estrias alveoladas, fortemente radiadas, fortemente convergentes para as extremidades, 48,479,31 um compr., 6,6-7,8 $\mu \mathrm{m}$ larg., 10-12 estrias alveoladas em $10 \mu \mathrm{m}$.

Hábitat: plâncton no Lago do IAG (SP294907); perifíton no hidrofitotério (SP255745), no Lago do IAG (SP294906), no Lago do Monjolo (SP294909) e no Lago das Ninféias (SP255743); metafíton/perifíton no brejo do Lago do IAG (SP294908).

Frenguelli (1933) elevou P. gibba Ehrenberg f. subundulata Mayer ex Hustedt ao nível variedade efetuando a combinação $P$. gibba Ehrenberg var. subundulata (Mayer) Frenguelli. Entretanto, a análise bibliográfica revelou ser mais frequiente a referência como f. subundulata Mayer ex Hustedt.

Frenguelli (1933) incluiu $P$. gibba Ehrenberg f. subundulata Mayer ex Hustedt e, questionavelmente, também Navicula sp. em Schmidt (1875: pl. 44, fig. 38) como sinônimos. A dúvida na citação de Navicula sp. como sinônimo de $P$. gibba Ehrenberg f. subundulata Mayer ex Hustedt em Schmidt (1875) demonstrou que este exemplar não é, de fato, um sinônimo, mas uma outra espécie. O espécime em Schmidt (1875) não possui ondulação, mas um intumescimento valvar mediano e as extremidades distais da rafe têm forma de baioneta.

Os espécimes do PEFI não apresentaram variação morfológica intra nem interpopulacional nas amostras 
de plâncton do hidrofitotério, de perifíton do Lago do IAG, do brejo do Lago do IAG e do Lago do Monjolo (figura 34), sendo que a área central da valva apresentou fáscia simétrica em todas as amostras. A amostra de perifíton do Lago das Ninféias (figuras 3536) incluiu alguns espécimes com fáscia assimétrica, sendo as estrias mais contínuas em uma das margens valvares, ao lado de outros espécimes com fáscia simétrica. É notável a variação referente à fáscia, porém, tal variação foi tão sutil que não justifica a separação dos espécimes em diferentes categorias taxonômicas.

Krammer (1992a) propôs $P$. subggiba Krammer var. undulata por diferir de $P$. gibba Ehrenberg var. subundulata (Mayer) Frenguelli nas extremidades valvares levemente capitadas, isto é, apresentaram o padrão subcapitado, além do esterno bem amplo. Krammer (2000) comentou, referindose à f. subundulata Mayer ex Hustedt, que seu tipo nomenclatural não se encontra devidamente esclarecido e necessita de estudos adicionais. Concluindo, Krammer (2000) não considerou estas espécies idênticas entre si e, portanto, sinônimos.

A atual população de $P$. gibba Ehrenberg f. subundulata Mayer ex Hustedt do PEFI é extremamente semelhante às de $P$. gibba Ehrenberg var. subundulata (Mayer) Frenguelli ilustradas em Hustedt (1930) e Frenguelli (1933).

Pinnularia grunowii Krammer, Diatoms of Europe 1: 100, pl. 77, fig. 7-14, pl. 81, fig. 10-17, pl. 82, fig. 7-8. 2000.

Figuras 11-13

Valvas lineares, 3-onduladas, ondulação central levemente menor, extremidades valvares capitadas, esterno da rafe linear, estreito, alargando para a área central, área central rômbica, lateralmente expandida, alcançando as margens, formando fáscia, rafe filiforme, extremidades proximais fletidas no mesmo sentido, extremidades terminais em forma de gancho, estrias alveoladas, radiadas, fortemente convergentes para as extremidades, 36,3-47,7 $\mu \mathrm{m}$ compr., 6,3-8,5 $\mu \mathrm{m}$ larg., 12-14 estrias alveoladas em $10 \mu \mathrm{m}$.

Hábitat: plâncton no Lago do IAG (SP294907).

A população estudada no presente estudo não apresentou variação morfológica.

Krammer(1992a, 1992b) incluiu vários morfotipos na circunscrição de P. mesolepta (Ehrenberg)W. Smith. A análise da espécie em Ehrenberg (1843), sua obra "princeps", mostrou que os representantes possuem valvas lineares, altamente onduladas e extremidades muito estreitas (rostradas, bem afiladas).

Krammer (2000) comentou que jamais observou um indivíduo que medisse $83 \mu \mathrm{m}$ compr., $13 \mu \mathrm{m}$ larg. e tivesse o contorno valvar igual ao do holótipo da espécie em Ehrenberg (1843: pl. 4(2), fig. 4).

A fim de agrupar melhor os exemplares antes identificados com P. mesolepta (Ehrenberg) W. Smith, Krammer (2000) fez novas combinações. Com isso, $P$. grunowii Krammer foi proposta para reunir uma boa parte dos indivíduos até então identificados com P. mesolepta (Ehrenberg) W. Smith. Pinnularia interrupta 'sensu' Hustedt (1930: fig. 573b) e $P$. mesolepta (Ehrenberg) W. Smith morfotipo 2 'sensu' Krammer (1992a: pl. 44, fig. 1-8, 10-12) foram consideradas idênticas a $P$. grunowii Krammer.

Pinnularia mesolepta (Ehrenberg) W. Smith é muito parecida com $P$. biceps Gregory, mas difere pelo tamanho das valvas (Krammer 2000). Trabalhos mais antigos como, por exemplo, o de Patrick \& Reimer (1966) difereriram $P$. biceps Gregory de $P$. mesolepta (Ehrenberg) W. Smith, principalmente, pelas margens valvares, que são retas ou levemente côncavas em $P$. biceps e trionduladas em $P$. mesolepta. Finalmente, $P$. septentrionalis Krammer é distinta de $P$. grunowii Krammer, principalmente, por apresentar as ondulações das valvas mais evidentes, a rafe lateral, o esterno moderadamente amplo e as medidas maiores (42-70 um compr., 10-15 um larg., 10-11 estrias alveoladas em $10 \mu \mathrm{m})$.

Pinnularia joculata (Manguin) Krammer in LangeBertalot, Diatoms of Europe 1: 116, pl. 13, fig. 5-9, pl. 88, fig. 42-43. 2000 = Pinnularia interrupta W. Smith var. joculata Manguin in Bourrely \& Manguin, Algues d'eau douce de Guadeloupe. 77, pl. 5, fig. 112a-b. 1952.

Figura 2

Valvas linear-lanceoladas, extremidades valvares capitadas, esterno da rafe formando um espaço linearlanceolado amplo com a área central, área central lateralmente expandida, alcançando as margens, formando fáscia ampla, rafe filiforme, extremidades proximais em forma de poros pequenos, sutilmente fletidas no mesmo sentido, extremidades terminais em forma de foice, estrias alveoladas, radiadas, convergentes para as extremidades, 21,5-22,3 $\mu \mathrm{m}$ compr., 3,7-4,1 $\mu \mathrm{m}$ larg., 20 estrias alveoladas em $10 \mu \mathrm{m}$.

Hábitat: perifíton no hidrofitotério (SP255745). 
Krammer (2000) elevou ao nível espécie a variedade $P$. interrupta W. Smith var. joculata Manguin efetuando a combinação $P$. joculata (Manguin) Krammer.

Os exemplares em Krammer (2000) e Manguin (1952) possuem contorno valvar linear. Os da atual investigação possuem-no linear-lanceolado, semelhante ao que ocorre com a população da espécie em Metzeltin \& Lange-Bertalot (2007) proveniente da América do Sul, cujo contorno valvar variou de linear a linear-lanceolado. De acordo com Krammer (2000), entretanto, $P$. joculata (Manguin) Krammer é distinta por possuir o contorno valvar linear e fáscia ampla.

Pinnularia joculata (Manguin) Krammer difere de $P$. schroeterae Krammer, de acordo com Krammer (2000), por ter a razão maior entre o comprimento e a largura valvar e fáscia mais ampla. Além disso, $P$. schroeterae Krammer pode apresentar valvas elípitico-lanceoladas e onduladas.

Os espécimes ora identificados não apresentaram variação morfológica e encontram-se dentro dos limites métricos propostos por Manguin (1952), que são: 19,55-22 $\mu \mathrm{m}$ compr., 4-4,5 um larg. e 20 estrias alveoladas em $10 \mu \mathrm{m}$.

Pinnularia mayeri Krammer in Lange-Bertalot, Diatoms of Europe 1: 115, pl. 42, fig. 1-4. 1992a.

Figuras 14-20

Valvas linear-lanceoladas, extremidades valvares amplamente capitadas, esterno da rafe linear-lanceolado, estreito, área central romboidal, lateralmente expandida, alcançando as margens, formando fáscia simétrica ou assimétrica, rafe filiforme, extremidades proximais em forma de poros pequenos, fletidas no mesmo sentido, extremidades terminais em forma de gancho, estrias alveoladas, radiadas, convergentes para as extremidades, 40-47,2 $\mu \mathrm{m}$ compr., 5,7-6,4 $\mu \mathrm{m}$ larg., 13-15 estrias alveoladas em $10 \mu \mathrm{m}$.

Hábitat: perifíton no hidrofitotério (SP294903) e no Lago dos Bugios (SP294901).

Os espécimes do PEFI não apresentaram variação morfológica e métrica interpopulacional. Intrapopulacionalmente, entretanto, variaram em relação à fáscia, que ora se apresentou simétrica ora não.

A população desta espécie ilustrada por Krammer (2000) possui fáscia simétrica e, ainda, o número de estrias é menor (9-10 estrias alveoladas em $10 \mu \mathrm{m}$ ). Porém, os espécimes da população do PEFI com fáscia simétrica são extremamante semelhantes ao ilustrado por Krammer (1992b) sendo, muito provável, que a fáscia assimétrica seja uma variação morfológica da população do presente estudo. Ainda, em relação à amplitude métrica, Krammer (1992b) referiu 10-14 estrias alveoladas em $10 \mu \mathrm{m}$, variação esta muito próxima à da atual população.

Esta espécie é extremamante semelhante a $P$. polyonca (Brébisson) Smith var. similis (Krammer) Krammer, cujo basiônimo é P. mayeri Krammer var. similis Krammer. Porém, P. mayeri Krammer é menos robusta, possui eixo apical e transapical menores e maior densidade de estrias em $10 \mu \mathrm{m}$. O basiônimo de P. polyonca (Brébisson) Smith var. similis (Krammer) Krammer possui, em Krammer (1992a), a obra que contém a descrição original de $P$. mayeri, as seguintes dimensões: 52-82 $\mu \mathrm{m}$ compr., 8-10 $\mu \mathrm{m}$ larg. e 8-10 estrias alveoladas em $10 \mu \mathrm{m}$.

Pinnularia mayeri Krammer possui, como sinônimos taxonômicos, $P$. amphicephala Mayer e $P$. braunii (Grunow) Cleve var. amphicephala (Mayer) Hustedt. Hustedt (1930) propôs a última variedade diferenciando-a da típica da espécie por possuir valvas linear-lanceoladas e extremidades valvares fortemente capitadas.

Pinnularia mayeri Krammer aproxima-se, morfologicamente, de P. subcapitata Gregory e, especificamente conforme Krammer (2000), dos espécimes maiores de $P$. subcapitata Gregory var. elongata Krammer. Difere, contudo, porque $P$. mayeri Krammer possui as extremidades valvares amplamente capitadas, bem destacadas do corpo valvar, enquanto que $P$. subcapitata Gregory var. elongata Krammer as possui capitadas, porém, mais afiladas do que o corpo valvar.

Pinnularia schoenfelderi Krammer, Bibliotheca Diatomologica 26: 70, pl. 15, fig. 1-13. 1992a.

Figura 3

Valvas elíptico-lanceoladas, extremidades valvares atenuado-arredondadas, esterno da rafe linear, estreito, área central retangular, lateralmente expandida, alcançando as margens formando fáscia, rafe filiforme, extremidades proximais em forma de poros pequenos, fletidas no mesmo sentido, extremidades terminais em forma de foice, estrias alveoladas, radiadas, convergentes para as extremidades, ca. 34,3 $\mu \mathrm{m}$ compr., ca. 6,7 $\mu \mathrm{m}$ larg., ca. 15 estrias alveoladas em $10 \mu \mathrm{m}$. 

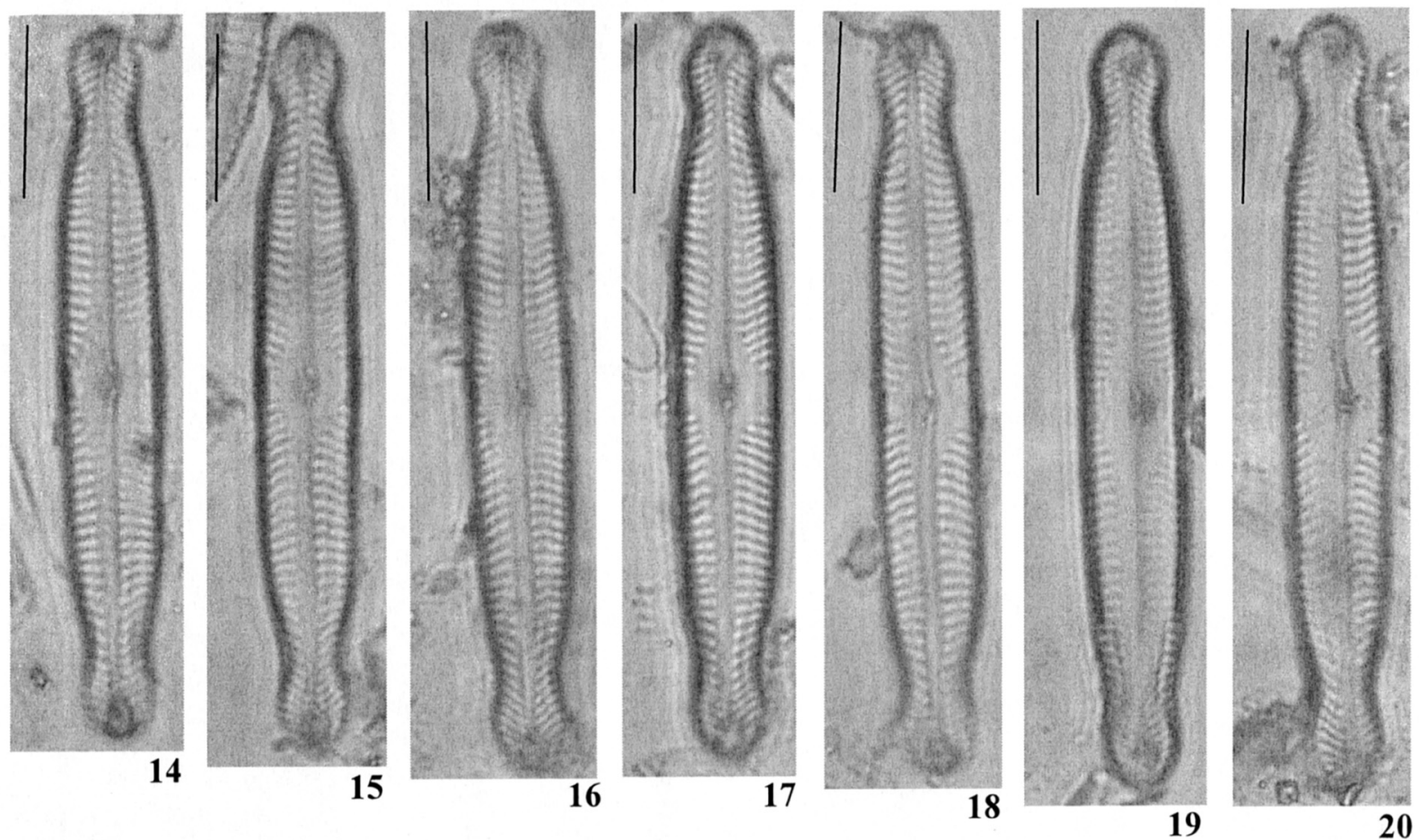

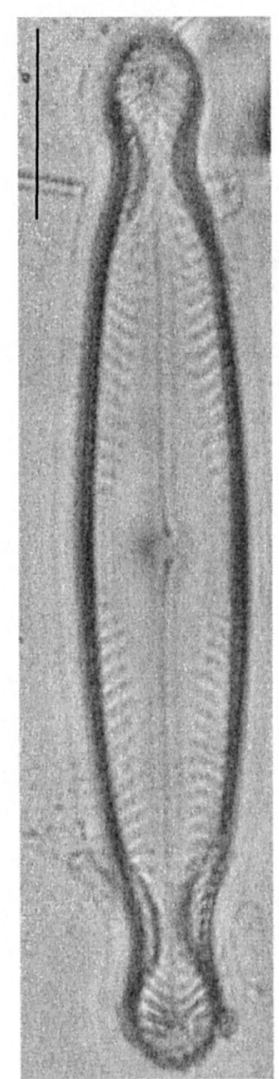

21

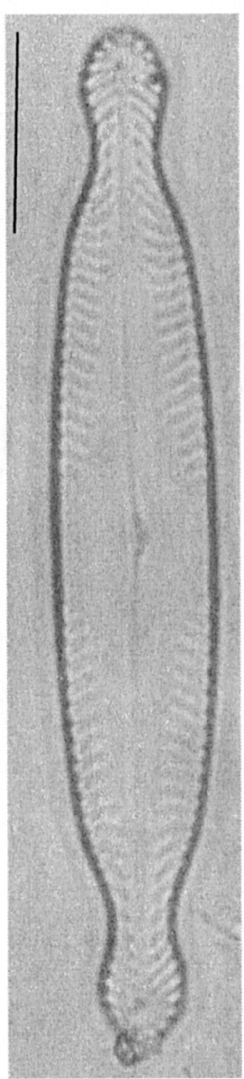

22

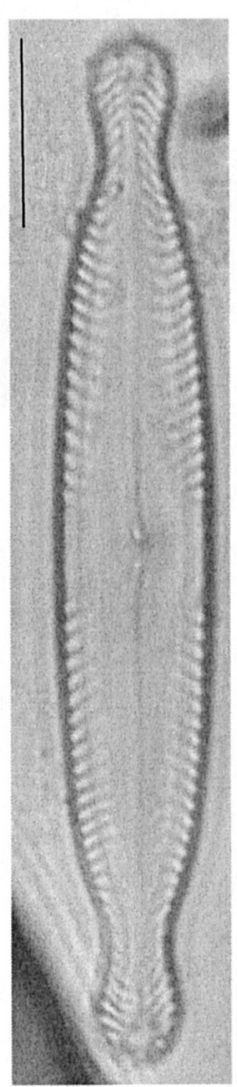

23

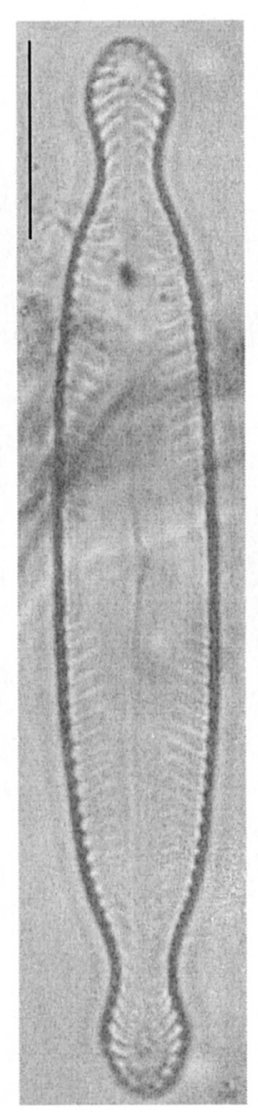

24

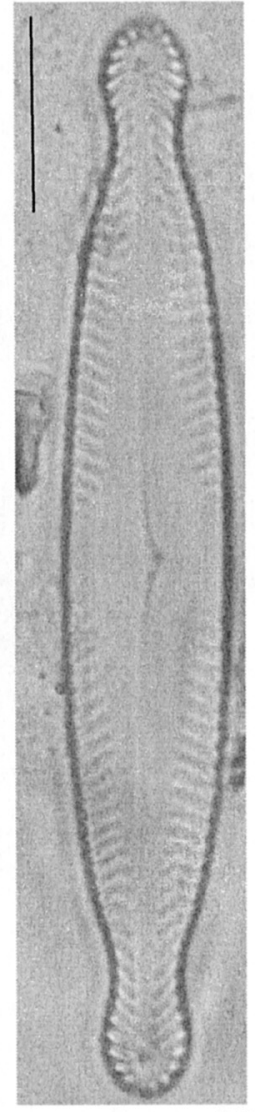

25

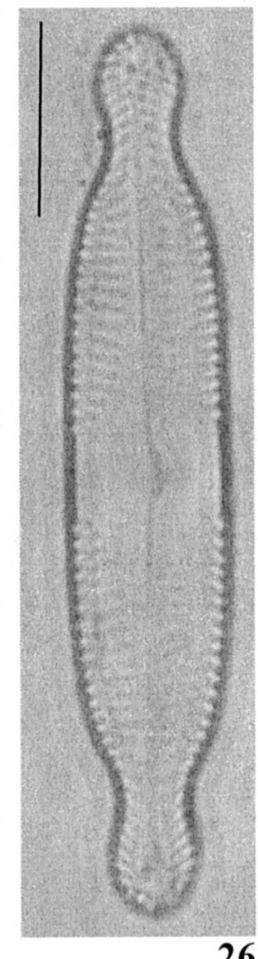

26

Figuras 14-20. Pinnularia mayeri. Figuras 21-25. P. brauniana var. sanctipaulensis. Figura 26. P. subanglica. Escalas valem $10 \mu \mathrm{m}$. 
Hábitat: plâncton no Lago dos Bugios (SP294902).

Foi encontrado apenas um espécime de $P$. schoenfelderi Krammer no PEFI, o qual foi extremamante semelhante, quanto a sua morfologia e medidas, aos espécimes ilustrados por Krammer (1992a, 2000).

Pinnularia schoenfelderi Krammer foi identificada por Hustedt (1930) como P. microstauron (Ehrenberg) Cleve var. brebissonii (Kützing) Hustedt f. diminuta Grunow. De acordo com Krammer (1992a, 2000), Hustedt (1930) confundiu o espécime que estudou com a verdadeira $P$. brebissonii (Kützing) Rabenhort var. diminuta (Grunow) Cleve.

Pinnularia schoenfelderi Krammer difere de $P$. obscuriformis Krammer, que apresenta como um sinônimo a verdadeira $P$. brebissonii (Kützing) Rabenhort var. diminuta (Grunow) Cleve, por possuir valvas lineares, com margens valvares retas. As extremidades são cuneadas, a área central mais ampla e as estrias mais espaçadas entre si (portanto, menor número de estrias em $10 \mu \mathrm{m}$ ) e fortemente convergentes para as extremidades.

De acordo com Krammer (2000), esta espécie lembra $P$. obscura Krasske e $P$. frauenbergiana Reichardt. Entretanto, P. obscura Krasske possui estrias radiadas, fortemente convergentes para as extremidades e mais espaçadas entre si, enquanto que $P$. frauenbergiana Reichardt tem valvas linearelípticas, extremidades menos afiladas, esterno e área central mais amplos, extremidades proximais da rafe muito levemente fletidas e estrias relativamente mais numerosas.

Pinnularia subanglica Krammer in Lange-Bertalot, Diatoms of Europe 1: 108, pl. 84, fig. 1-7, pl. 78, fig. 7. 2000.

Figura 26

Valvas lineares, extremidades valvares capitadas, esterno da rafe linear-lanceolado, pouco estendido, área central rômbica, expandida lateralmente, formando fáscia, rafe filiforme, extremidades proximais nitidamente fletidas no mesmo sentido, extremidades terminais em forma de gancho, estrias alveoladas, radiadas, convergentes para as extremidades, 36,1-45,3 $\mu \mathrm{m}$ compr., 6-8,6 $\mu \mathrm{m}$ larg., 12-13 estrias alveoladas em $10 \mu \mathrm{m}$.

Hábitat: plâncton no Lago do IAG (SP294907).

Esta espécie mostra considerável semelhança com $P$. brauniana (Grunow) Mills, P. latarea Krammer e $P$. rumrichae Krammer, sendo que a área central romboidal é a característica comum às quatro espécies. Porém, de acordo com Krammer (2000), P. brauniana (Grunow) Mills apresenta as valvas lanceoladas, margens convexas, extremidades valvares capitadas e com estrias, esterno lanceolado e área central formando fáscia. Em P. latarea Krammer, as valvas são lineares, com margens convexas e extremidades capitadas assumindo a forma de "pescoço" e com estrias, esterno lanceolado e amplo e área central formando uma fáscia ampla. Em $P$. rumrichae Krammer, as valvas são lineares, com margens retas e paralelas, extremidades capitadas formando um "pescoço" com estrias, esterno estreito e área central formando uma fáscia ampla.

Pinnularia subcapitata Gregory var. subcapitata, Quarterly Journal of Microscopical Science 4: 9, pl. 1, fig. 30. 1856.

Figuras 4-8

Valvas lineares, extremidades valvares subcapitadas, esterno da rafe linear, estreito, área central romboidal, variável, lateralmente expandida em ambas as margens, formando fáscia bilateral ou lateralmente expandida em apenas uma margem, formando fáscia unilateral, rafe filiforme, extremidades proximais fletidas no mesmo sentido, extremidades terminais em forma de foice, estrias alveoladas, radiadas, convergentes para as extremidades, 34,544,3 um compr., 5,5-6,7 $\mu \mathrm{m}$ larg., 13-14 estrias alveoladas em $10 \mu \mathrm{m}$.

Hábitat: plâncton no Lago dos Bugios (SP294902) e no Lago das Ninféias (SP255744); perifíton no Lago dos Bugios (SP294901), no Lago das Garças (SP255751) e no Lago das Ninféias (SP255743).

Notou-se grande variabilidade morfológica ao consultar os trabalhos com referência a $P$. subcapitata Gregory var. subcapitata. Assim, espécimes representantes da variedade típica possuem contorno valvar linear, linear-elíptico ou linearlanceolado, com as extremidades valvares capitadas a sub-capitadas, esterno linear estreito a levemente linear-lanceolado e área central podendo ou não formar fáscia. Para outros autores, entretanto, algumas dessas variações foram suficientes para a proposição de variedades taxonômicas.

De acordo com Brassac \& Ludwig (2006), autores como Germain (1981) e Krammer \& LangeBertalot (1986) comentaram e documentaram a variabilidade morfológica em $P$. subcapitata Gregory 
var. subcapitata no que tange ao contorno valvar, ao esterno e à área central.

Krammer (2000) aprofundou o estudo de $P$. subcapitata Gregory var. subcapitata propondo novas variedades e novas combinações nomenclaturais a vários espécimes referidos na literatura como de $P$. subcapitata Gregory. Conforme Krammer (2000), Patrick \& Reimer (1966) registraram uma mistura de vários táxons sob o nome $P$. subcapitata Gregory var. subcapitata. Por exemplo, Patrick \& Reimer (1966: pl. 55, fig. 10) é, atualmente, P. sinistra Krammer (1992a).

Os indivíduos presentemente analisados mostraram variabilidade morfológica intrapopulacional quanto à forma da área central (perifíton, Lago das Ninféias, fig. 4-8). A população analisada em todas as amostras apresentou área central romboidal, sendo que em alguns espécimes formou-se uma fáscia bilateralmente estendida enquanto que, em outros, a fáscia foi mais ampla e, em ainda outros, diminuiu gradativamente de tamanho em uma das margens ficando, consequentemente, mais estreita até à interrupção total das estrias na área central, formandose uma fáscia. No outro extremo, a fáscia foi estendida unilateralmente, com as estrias alveoladas contínuas em uma das margens valvares. Os espécimes com fáscia bilateral foram muito semelhantes aos ilustrados por Bigunas (2005). O segundo extremo citado caracteriza $P$. subcapitata Gregory var. semicruciata Metzeltin \& Krammer se se considerar Metzeltin \& Lange-Bertalot (1998).

Ao propor a var. semicruciata, Metzeltin \& Krammer (1998) colocaram que seus representantes apresentam uma área central dilatada em um lado e estendida até à margem valvar no outro. Os referidos autores propuseram esta variedade com uma diagnose que salientou unicamente as diferenças entre a novidade taxonômica e $P$. subcapitata Gregory var. elongata Krammer. De acordo com Metzeltin \& Lange-Bertalot (1998), além da fáscia bilateral, a var. elongata Krammer também possui 10-12 estrias alveoladas em 10 um e não 13-14.

Optou-se por identificar os espécimes neste estudo com os da variedade típica da espécie, pois a var. elongata Krammer se caracteriza pela presença de rafe lateral, 10-11 estrias alveoladas em $10 \mu \mathrm{m}$ e razão comprimento/largura valvar superior a 7,5. Na população atualmente identificada, a rafe não se apresentou em posição lateral, as estrias variaram de 13-14 em $10 \mu \mathrm{m}$ e a razão comprimento/largura valvar entre 6,3-6,6, condizendo muito mais com a variedade típica da espécie, cuja rafe não é lateral, tem 11-13 estrias alveoladas em $10 \mu \mathrm{m}$ e razão comprimento/ largura valvar variando até 6 .

Em relação à var. semicruciata Metzeltin \& Krammer, foi encontrado um contínuo nas populações do PEFI, que incluiu os espécimes com fáscia unilateral e bilateral, não sendo possível separá-los em duas subpopulações. Corroborando a afirmação anterior, Germain (1981) ilustrou e comentou que $P$. subcapitata Gregory var. subcapitata apresenta área central variável, com certos indivíduos em que as estrias alveoladas são interrompidas na região central e outros em que uma margem valvar apresenta estrias alveoladas contínuas. Apesar de Krammer (2000) ter comentado que Patrick (Patrick \& Reimer 1966) misturou alguns espécimes que não fazem parte da variedade típica da espécie, a referida autora afirmou que a ilustração original de Gregory mostra uma pequena área central e nenhuma indicação da presença de fáscia. Esta afirmação de Patrick (Patrick \& Reimer 1966) é evidente quando se observa a ilustração de $P$. subcapitata Gregory que Krammer (1992a: pl. 37, fig. 17) reproduziu da obra original de Gregory, de 1856. Observa-se nessa ilustração que o indivíduo ilustrado por Gregory apresenta estrias alveoladas contínuas pela margem valvar.

Pinnularia subcapitata Gregory var. subcapitata difere de $P$. pisciculus Ehrenberg, que possui extremidades subcapitadas alongadas e estrias paralelas entre si (observações feitas através da análise da obra original, de Ehrenberg 1843) e de P. pisciculus Ehrenberg var. angusta Metzeltin \& Krammer, a qual possui corpo valvar mais alongado, fáscia mais ampla e estrias mais distantes uma da outra.

Pinnularia subgibba Krammer var. lanceolata Gaiser \& Johanser, Diatom Research 15(1): 117, fig. 9091. 2000.

Figuras 31-33

Valvas linear-lanceoladas, extremidades valvares subcapitadas, esterno da rafe formando um espaço lanceolado amplo com a área central, área central lateralmente expandida, alcançando as margens, formando fáscia, rafe filiforme, levemente ondulada, extremidades proximais levemente dilatadas, fletidas no mesmo sentido, extremidades terminais em forma de gancho, estrias alveoladas, radiadas, convergentes para as extremidades, 56-68,9 $\mu \mathrm{m}$ compr., 8-9,9 $\mu \mathrm{m}$ larg., 9-11 estrias alveoladas em $10 \mu \mathrm{m}$. 
Hábitat: plâncton no Lago do IAG (SP294907); perifíton no hidrofitotério (SP255745), no Lago dos Bugios (SP255747), no Lago do Monjolo (SP294909) e no Lago das Ninféias (SP255743); metafíton/ perifíton no brejo do Lago do IAG (SP294908).

As populações presentemente estudadas não apresentaram variação morfológica nem métrica, seja em nível intrapopulacional seja em nível interpopulacional. Porém, com relação aos espécimes ilustrados por Gaiser \& Johansen (2000), as extremidades são relativamente menos afiladas. Os referidos autores descreveram as extremidades valvares como rostradas.

Diversos trabalhos citaram como $P$. gibba Ehrenberg var. gibba o que hoje é ilustrado como $P$. subgibba Krammer var. lanceolata Gaiser \& Johanser. A análise do tipo nomenclatural em Ehrenberg [1943: pl. 2, fig. 1(24), pl. 3, fig. 1(4)] demonstrou que os dois espécimes são bem diferentes um do outro. Deles, o primeiro possui valvas lineares, com um leve intumescimento mediano e extremidades arredondadas, as quais são contínuas com o corpo valvar, enquanto que o segundo possui valvas linear-elípticas e extremidades amplamente capitadas. $\mathrm{O}$ esterno é linear e estreito e o padrão de estriação é paralelo nos dois indivíduos. Assim, os espécimes do PEFI não mostram semelhança com $P$. gibba Ehrenberg.

Outros trabalhos identificaram espécimes de $P$. subgibba Krammer var. lanceolata Gaiser \& Johanser como de P. gibba Ehrenberg var. sancta (Grunow ex Cleve) Meister. Entretanto, de acordo com Cleve (1894-1895) que propôs $P$. stauroptera Grunow var. sancta Grunow ex Cleve, ou seja, o basiônimo de $P$. gibba Ehrenberg var. sancta (Grunow ex Cleve) Meister, as valvas são amplamente intumescidas na região central, o esterno é amplo e as medidas ca. 110 $\mu \mathrm{m}$ compr., ca. $15 \mu \mathrm{m}$ larg. e 10-11 estrias alveoladas em $10 \mu \mathrm{m}$. Cleve (1894-1895) não ilustrou o material que estudou.

De acordo com Gaiser \& Johansen (2000), P. subgibba Krammer var. lanceolata Gaiser \& Johanser pertence ao complexo de espécies $P$. gibba/P. gibbiformis. Mas, difere de $P$. gibba Enrenberg por não ter as extremidades valvares capitadas e, ao contrário de $P$. gibbiformis Krammer, ter a razão comprimento/ largura valvar maior sem, contudo, identificar os valores; também, pela área central formando fáscia. Gaiser \& Johansen (2000) ainda relataram que a população estudada de $P$. subgibba Krammer var. lanceolata Gaiser \& Johanser apresentou variação no que tange à largura do esterno e da área central.
Metzeltin \& Lange-Bertalot (2002: pl. 71, fig. 5) ilustraram um exemplar muito semelhante aos presentemente inventariados, com valvas linearlanceoladas, e o identificaram com $P$. subgibba Krammer, porém, com a ressalva de poder vir a ser uma nova variedade.

Esta variedade difere da típica da espécie, principalmente, por não apresentar valvas lineares e pelo esterno e área central serem amplamente lanceolados.

A var. undulata Krammer e var. sublinearis Krammer diferem quanto às valvas, que são lineares e levemente onduladas na primeira das duas variedades. $\mathrm{Na}$ segunda, além das valvas, que são lineares, as margens são paralelas e as extremidades arredondadas. A var. sublinearis Krammer foi identificada junto com var. lanceolata Gaiser \& Johanser a partir de material perifítico do hidrofitotério, no entanto, não foi atualmente observado um contínuo de variação das características de ambas que justificasse a união de todos os espécimes em uma única espécie.

Metzeltin et al. (2005) descreveram uma nova espécie, $P$. hudsonii. Numa primeira aproximação, a análise desta espécie mostrou algumas semelhanças com a atual população do PEFI, contudo, uma avaliação mais detalhada revelou que os espécimes representantes de $P$. subgibba Krammer var. lanceolata Gaiser \& Johanser possuem valvas linear-lanceoladas, no entanto apresentam o eixo transapical maior e as extremidades não protraídas, sem o padrão subcapitado, porém afiladas em alguns casos, assumindo um padrão cuneado.

Pinnularia subgibba Krammer var. sublinearis Krammer in Lange-Bertalot, Diatoms of Europe 1: 85, pl. 65, fig. 14. 2000.

Figura 37

Valvas lineares, extremidades valvares arredondadas, esterno da rafe lanceolado, amplo, área central romboidal, lateralmente expandida, alcançando as margens, formando fáscia, rafe filiforme, levemente lateral, extremidades proximais em forma de poros pequenos, fletidas no mesmo sentido, extremidades terminais em forma de gancho, estrias alveoladas, radiadas, convergentes para as extremidades,

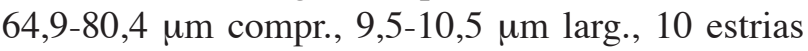
alveoladas em $10 \mu \mathrm{m}$.

Hábitat: plâncton no Lago do IAG (SP294907); perifíton no hidrofitotério (SP255745) e no Lago do IAG (SP294906). 

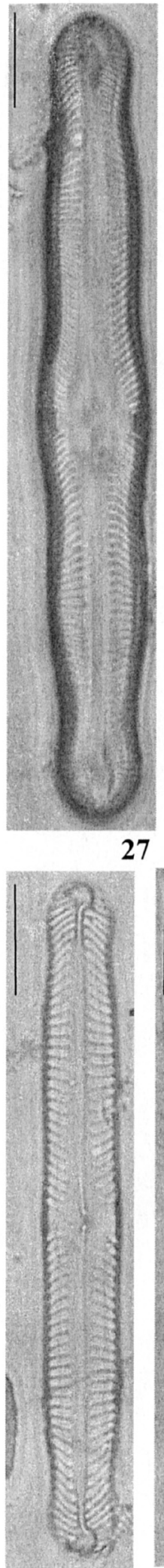

34

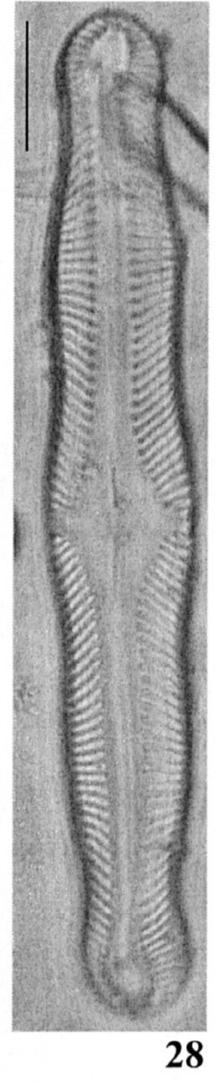

28

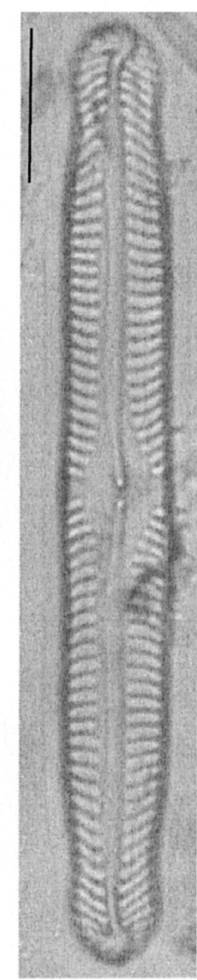

36
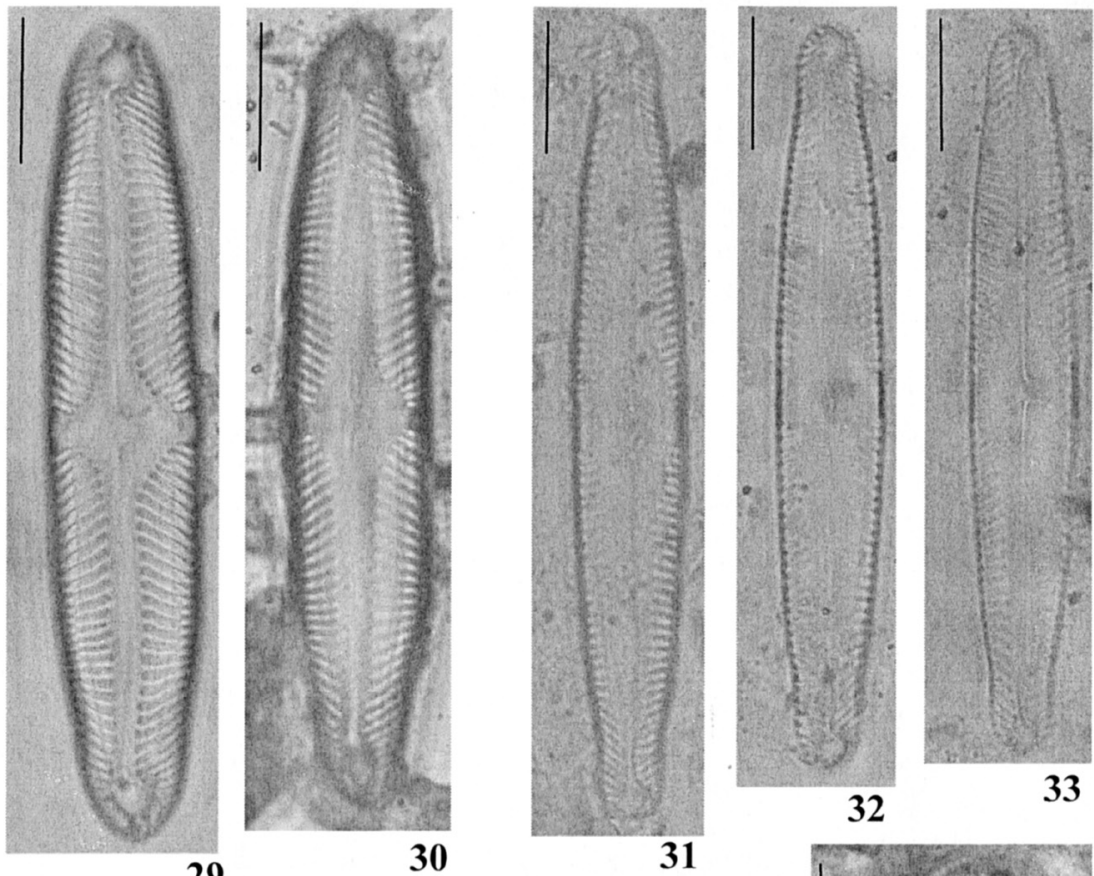

30

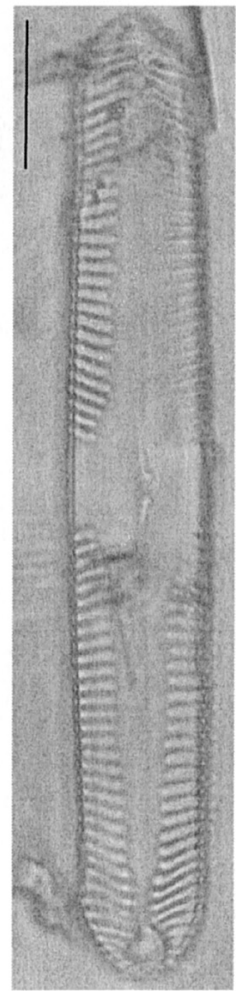

37

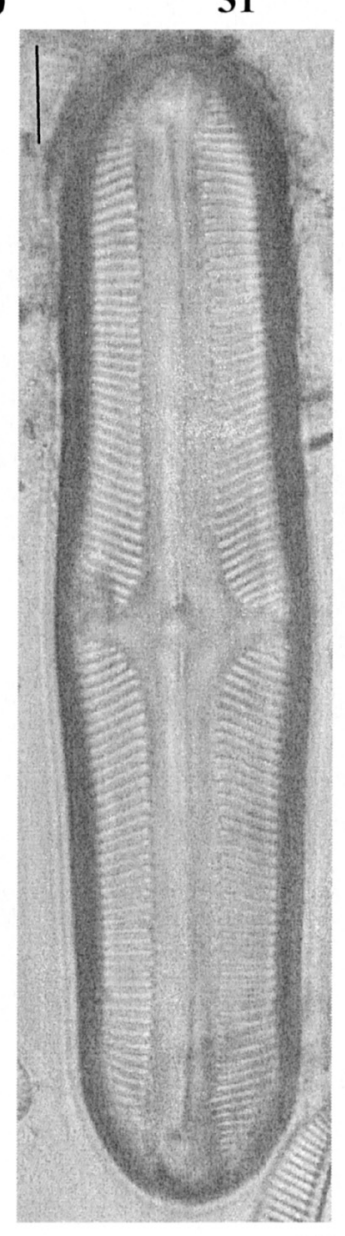

38

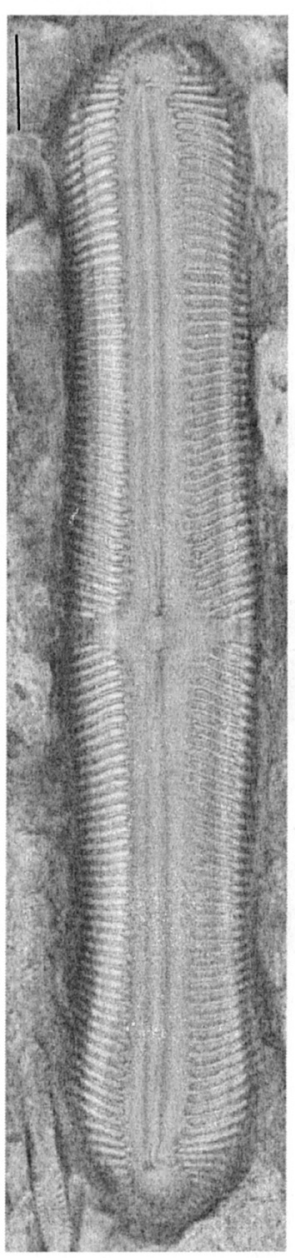

39

Figuras 27-28. Pinnularia divergens var. mesoleptiformis. Figuras 29-30. P. divergens var. divergens. Figuras 31-33. P. subgibba var. lanceolata. Figuras 34-36. P. gibba var. subundulata. Figura 37. P. subgibba var. sublinearis. Figuras 38-39. P. divergens var. malayensis. Escalas valem $10 \mu \mathrm{m}$. 
Krammer (2000) diferiu esta variedade da típica da espécie por apresentar extremidades não protraídas, mas arredondadas, e margens paralelas entre si. Tais características foram integralmente observadas durante a análise do material do PEFI. Além disso, os representantes da variedade não-típica apresentaram o esterno mais amplo.

Os presentes exemplares são idênticos aos de P. subgibba Krammer var. sublinearis Krammer em Krammer (2000) e não apresentaram variação morfológica significativa intra nem interpopulacional.

Existe bastante semelhança entre os representanes desta espécie, os de $P$. gibba Ehrenberg var. linearis Hustedt e os de $P$. abaujensis Pantošek var. linearis (Hustedt) Patrick. A este respeito, Krammer (2000) suscitou dúvidas quanto à sinonimização da var. linearis Hustedt e var. sublinearis Krammer. Para o referido autor, alguns registros de citações da var. linearis Hustedt são, na realidade, da var. sublinearis Krammer.

Simonsen (1987) afirmou que Hustedt (1930) falhou ao definir ou nomear os espécimes de $P$. gibba Ehrenberg var. linearis Hustedt. Simonsen (1987) considerou lectótipo da var. linearis as ilustrações em sua obra à pl. 195, fig. 1-2. A análise das ilustrações em Simonsen (1987) permitiu ver que as valvas possuem extremidades relativamente mais afiladas, área central mais estreita e padrão de estriação também diferente (estrias levemente radiadas a paralelas entre si na região central e levemente convergentes a paralelas entre si no sentido das extremidades) diferindo, assim, do holótipo em Hustedt (1930). Para Krammer (2000), Simonsen (1987) designou lectótipos tais espécimes, mas estes não estão conforme o holótipo em Hustedt (1930).

A respeito das ilustrações em Simonsen, Simonsen (1987: pl. 195, fig. 2, de P. gibba Ehrenberg var. linearis 'sensu' Simonsen) foi considerada por Krammer (2000) uma nova variedade, P. tirolenses (Metzeltin \& Krammer) Krammer var. julma Krammer; e Simonsen (1987: pl. 195, fig. 1) um representante do complexo P. crucifera Cleve-Euler.

Pinnularia tabellaria Ehrenberg, Abhandlungen der Königlichen Akademie der Wissenschaften zu Berlin 1841: 422, pl. 2(1), fig. 26, pl. 3(1), fig. 7, pl. 3(3), fig. 6, pl. 3(4), fig. 5, pl. 4(1), fig. 4. 1841 (1843).

Figuras 45-46
Valvas lineares, intumescidas na região central, extremidades valvares capitadas a levemente arredondado-cuneadas, esterno da rafe linear, pouco expandido, área central rômbica a circular, rafe complexa, lateral, extremidades proximais pouco dilatadas, sutilmente fletidas no mesmo sentido, extremidades terminais em forma de baioneta, estrias alveoladas, radiadas, convergentes para as extremidades, 70,9-102,4 $\mu \mathrm{m}$ compr., 11,3-13,9 $\mu \mathrm{m}$ larg., 12-13 estrias alveoladas em $10 \mu \mathrm{m}$.

Hábitat: perifíton no Lago das Ninféias (SP255743).

Pinnularia tabellaria Ehrenberg lembra muito P. luculenta Schmidt. Brassac \& Ludwig (2006) comentaram tal semelhança e afirmaram que em $P$. tabellaria Ehrenberg a área central é lanceolada, alargando no sentido de um esterno mais amplo e as extremidades valvares são mais cuneadas, enquanto que $P$. luculenta Schmidt apresenta área central bem definida, de formato circular, esterno estreito e extremidades valvares arredondadas. Ainda, de acordo com as mesmas autoras, Schmidt (1875) afirmou que $P$. luculenta Schmidt apresenta comprimento valvar menor do que P. tabellaria Ehrenberg. Tal afirmação é verdadeira ao analisar as ilustrações de $P$. tabellaria Ehrenberg e P. luculenta Schmidt em Schmidt (1875: pl. 43 , fig. 4 e pl. 43 , fig. 12 , respectivamente). Ao retornar, porém, à obra original de $P$. tabellaria Ehrenberg [Ehrenberg 1843: 422, pl. 2(1), fig. 26, pl. 3(1), fig. 7, pl. 3(3), fig. 6, pl. 3(4), fig. 5, pl. 4(1), fig. 4], as ilustrações mostram indivíduos com pequena variação nas extremidades valvares desde amplamente arredondadas até arredondado-cuneadas. Todos os indivíduos ilustrados possuem esterno da rafe linear estreito e área central circular. Em suma, é questionável a separação das espécies $P$. tabellaria Ehrenberg e $P$. luculenta Schmidt. Krammer (2000) considerou $P$. luculenta Schmidt e P. tabellaria Ehrenberg sinônimos. Para ele, provavelmente alguns registros de $P$. luculenta Schmidt em literatura devem ser, de fato, de $P$. tabellaria Ehrenberg como, por exemplo, a ilustração de $P$. luculenta Schmidt em Hustedt (1938: pl. 23, fig. 16). Observando as ilustrações em Hustedt (1938: pl. 23, fig. 16-17, respectivamente, de $P$. luculenta e $P$. tabellaria), é impossível separar esses dois espécimes em categorias taxonômicas diferentes. Para Reichardt \& Jahn (1995), P. luculenta Schmidt concorda completamente com as formas acima mencionadas de $P$. tabellaria Ehrenberg.

Em relação à análise da população dos indivíduos do presente estudo, observou-se uma série contínua no 

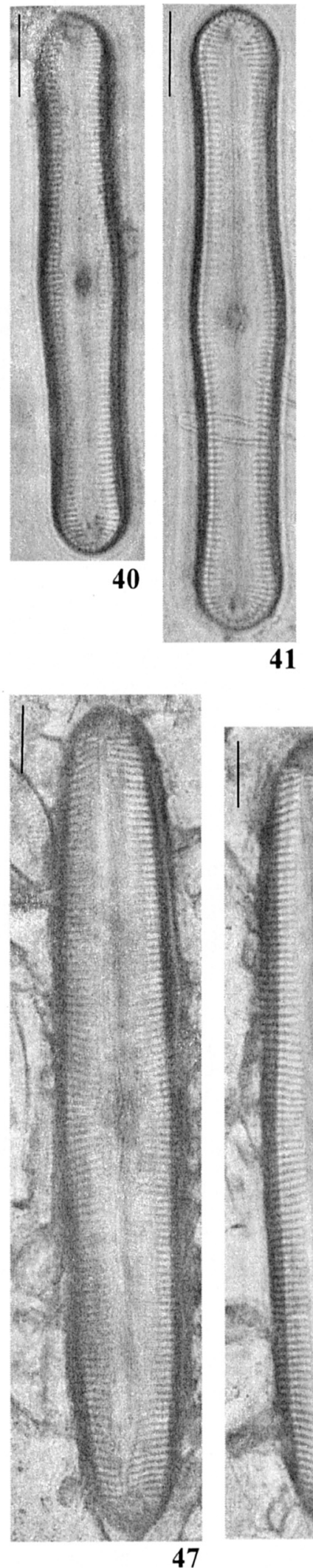

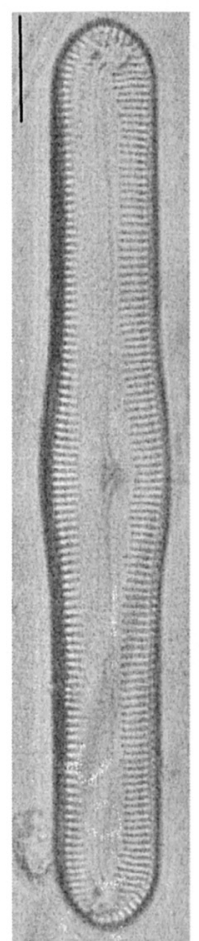

42

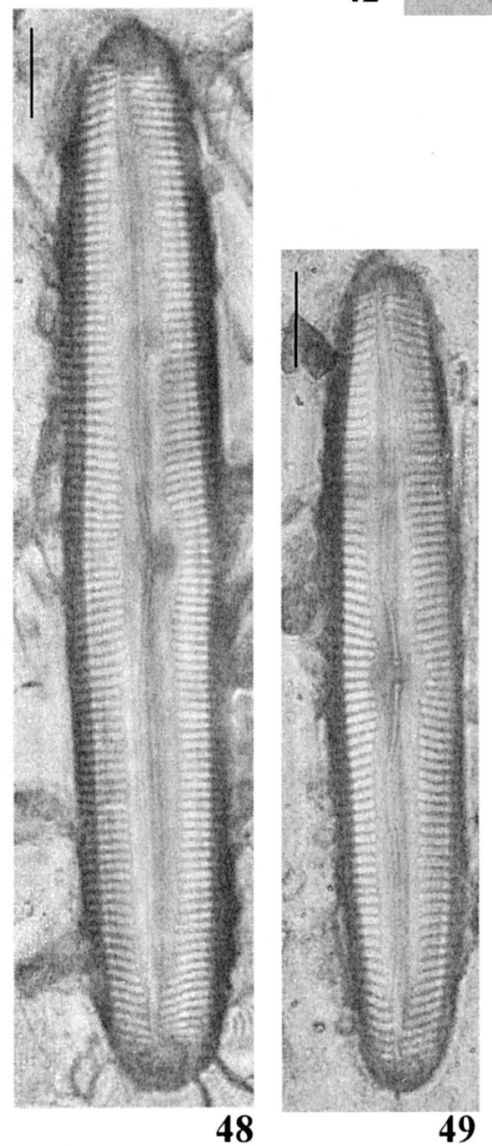

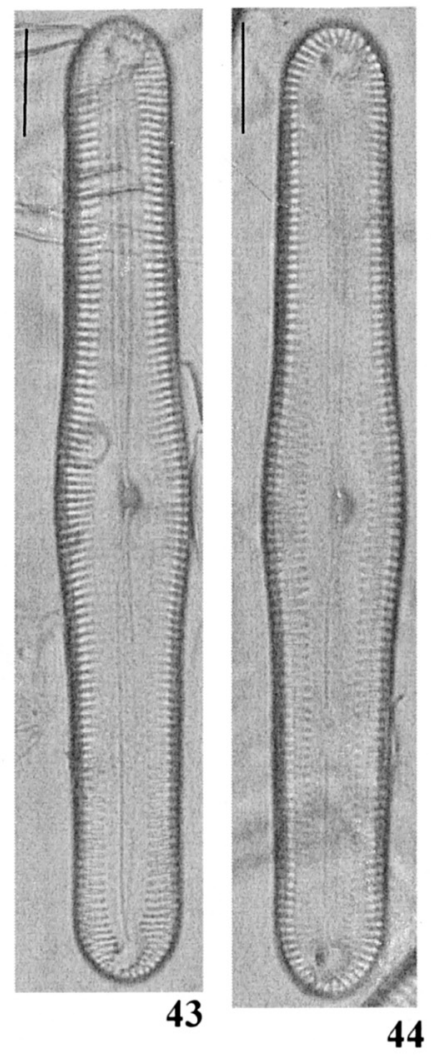
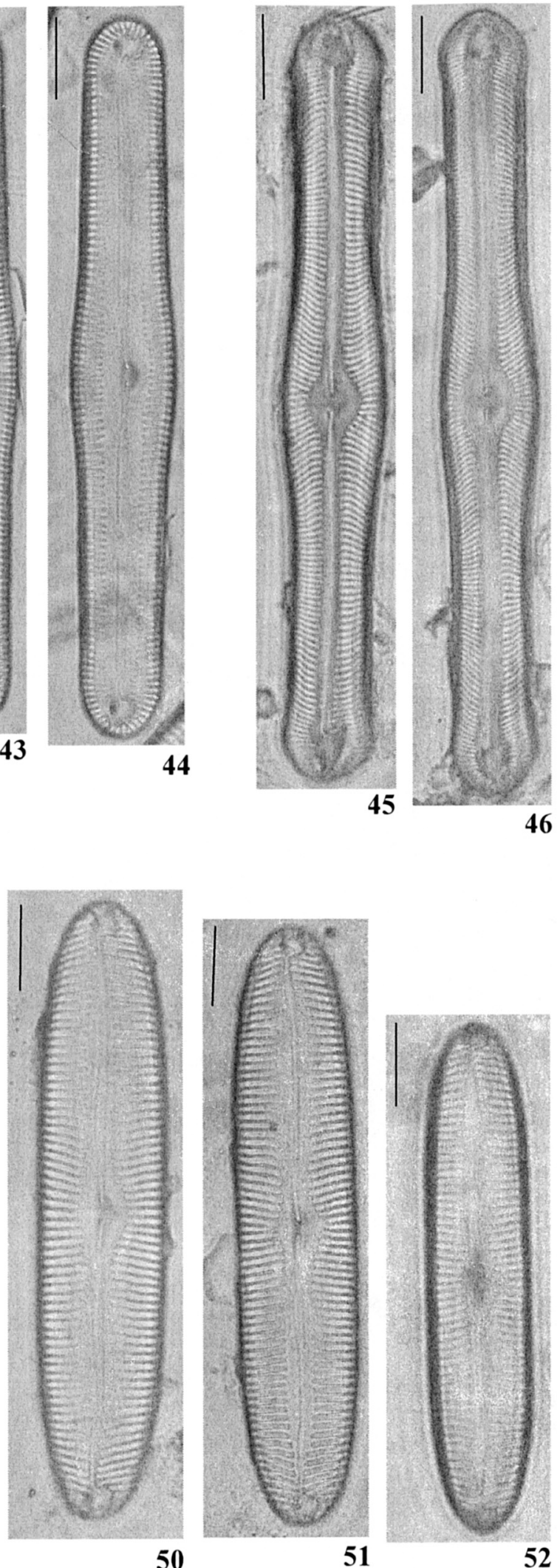

Figuras 40-41. Pinnularia acrosphaeria var. acrosphaeria. Figuras 42-44. P. acrosphaeria var. tumidula. Figuras 45-46. P. tabellaria. Figuras 47-49. P. viridiformis var. viridiformis. Figuras 50-52. P. viridis var. viridis. Escalas valem $10 \mu \mathrm{m}$. 
que tange às extremidades valvares, desde arredondada até levemente arredondado-cuneada e a área central desde rômbica até circular.

Pinnularia viridiformis Krammer var. viridiformis, Bibliotheca Diatomologica 26: 160, pl. 1, fig. 4, pl. 4, fig. 1-4, pl. 68, fig. 1-4, pl. 69, fig. 1-5. 1992a.

Figuras 47-49

Valvas elíptico-lenceoladas, levemente intumescidas na região central, extremidades valvares acuminado-arredondadas, esterno da rafe linear, expandido, levemente mais alargado para a área central, área central levemente diferenciada do esterno, arredondada, assimétrica, rafe lateral, ondulada, extremidades proximais levemente fletidas no mesmo sentido, extremidades terminais em forma de baioneta, estrias alveoladas, levemente radiadas, suavemente convergentes para as extremidades, 74,9126,5 $\mu \mathrm{m}$ compr., 14,5-19,1 $\mu \mathrm{m}$ larg., 9-10 estrias alveoladas em $10 \mu \mathrm{m}$.

Hábitat: perifíton no hidrofitotério (SP255745) e no Lago das Ninféias (SP255743).

Krammer (1992a) propôs o nome substituto $P$. viridiformis para $P$. viridis (Nitzsch) Ehrenberg var. minor Cleve. De acordo com as descrições do complexo viridis/viridiformis em Krammer (2000), as duas espécies diferem entre si, principalmente, pela forma valvar, mas também pela rafe semicomplexa. Em ambas as espécies, as valvas apresentam contorno linear e as margens são paralelas a levemente convexas ou trionduladas; no entanto, de acordo com Krammer (2000), em P . viridis (Nitzsch) Ehrenberg as valvas vão estreitando para as extremidades arredondadas, enquanto que isto não ocorre em $P$. viridiformis Krammer.

Para Patrick \& Reimer (1966), P. viridis (Nitzsch) Ehrenberg var. minor Cleve difere da variedade típica da espécie, principalmente, por apresentar esterno mais amplo e área central mais diferenciada. Ainda de acordo com Krammer (2000), é necessária mais investigação sobre $P$. viridiformis Krammer para que se entenda, de forma precisa, a extensão da variação morfológica do esterno, da área central e do contorno valvar.

Populações de $P$. viridiformis Krammer foram vistas em material coletado no hidrofitotério e no Lago das Ninféias (fig. 47-49) e em nenhuma delas foi observada variação morfológica intra nem interpopulacional. Tais indivíduos foram, isto sim, muito semelhantes aos referidos por Krammer (2000) como morfotipo 4 da mesma espécie. Diferem dos demais morfotipos em Krammer (2000) pelo seguinte: do morfotipo 1, principalmente, porque as extremidades valvares são mais cuneadas e afiladas e o esterno é estreito no morfotipo 1; o morfotipo 2 possui a relação comprimento/largura valvar menor, aparecendo mais largos e com a área central menos diferenciada do esterno, além de ser menos assimétrica; no morfotipo 3, as valvas são mais linearelípticas; finalmente, no morfotipo 5 as valvas são rombóide-lineares.

As populações do PEFI apresentaram, ainda, certa semelhança morfológica com os representantes de $P$. neomajor Krammer var. neomajor. Nesta espécie, as extremidades são relativamente mais largas, o esterno é mais amplo e, em uma das margens, as estrias alveoladas são contínuas e todas do mesmo tamanho, não se observando alargamento do esterno e conseqüente diminuição do tamanho das estrias, enquanto que na outra margem ocorre diminuição do tamanho das estrias quando estas atingem a área central sendo, portanto, circulares em um dos lados. Além dessas diferenças, as medidas também são distintas, sendo maiores (160-230 um compr., 24-30 $\mu \mathrm{m}$ larg.) em P. neomajor Krammer. Nos exemplares do PEFI, as extremidades são mais afiladas, o esterno mais estreito, a área central assimétrica, contudo, circular em ambos os lados, e as medidas estão dentro da faixa de variação do morfotipo 4 de $P$. viridiformis Krammer (72-130 $\mu \mathrm{m}$ compr., 14,7-18,8 $\mu \mathrm{m}$ larg.).

Pinnularia viridis (Nitzsch) Ehrenberg var. viridis, Abhandlungen der Königlichen Akademie der Wissenschaften zu Berlin 1841: pl. 1(1), fig. 7, pl. 1(3), fig. 3, pl. 1(4), fig. 3, pl. 2(1), fig. 22, pl. 2(3), fig.1, pl. 2(5), fig. 2, pl. 2(6), fig. 21, pl. 3(1), fig. 1-2. 1841 (1843) $\equiv$ Bacillaria viridis Nitzsch, Neue Schriften der Naturwissenschaftlich gesammt, Halle 3(1): 97, pl. 6, fig.1-3.1817.

Figuras 50-52

Valvas linear-elípticas, extremidades valvares acuminado-arredondadas, esterno da rafe linear, estreito, expandido para a área central, área central elíptica, rafe complexa, levemente ondulada, extremidades proximais em forma de poros pequenos, fletidas no mesmo sentido, extremidades terminais em forma de baioneta, estrias alveoladas, levemente radiadas, suavemente convergentes para as extremidades, 56-98,5 $\mu \mathrm{m}$ compr., 12,3-17,1 $\mu \mathrm{m}$ larg., 8-11 estrias alveoladas em $10 \mu \mathrm{m}$.

Hábitat: perifíton no Lago das Ninféias (SP255743). 
Obras recentes propuseram novas espécies e variedades de Pinnularia tais como, por exemplo, $P$. viridiformis Krammer var. viridiformis e $P$. neomajor Krammer var. intermedia (Cleve) Krammer a partir de $P$. viridis (Nitzsch) Ehrenberg. A análise desses trabalhos acarretou em dificuldade na identificação correta das populações do PEFI. Assim, para a melhor identificação de todos os indivíduos que se enquadram neste complexo, fez-se necessária a análise e a comparação dos presentes com os exemplares de $P$. viridis (Nitzsch) Ehrenberg em Ehrenberg (1843).

Para Krammer (2000), o autor base para a identificação de $P$. viridis é Ehrenberg (1843) já que não se conhece o material-tipo (Bacillaria viridis Nitzsch) de $P$. viridis (Nitzsch) Ehrenberg.

As ilustrações em Ehrenberg [1843: pl. 2(1), fig. 22, pl. 3(1) fig. 1-2] são muito parecidas com as dos representantes da população do PEFI. Elas mostram extremidades arredondadas, esterno estreito, porém, com as estrias não alcançando a rafe e área central visível e elíptica. As ilustrações acima da pl. 3(1), fig. 1-2 são ainda mais semelhantes por causa das valvas linear-elípticas, enquanto que a da pl. 2(1), fig. 22 mostra valvas lineares. A ilustração da pl. 3(1), fig. 1 é bem mais semelhante, pois, além do contorno linearelíptico, o padrão de estriação é levemente radiado a levemente convergente para as extremidades.

Não foi vista variação métrica nem morfológica intrapopulacional entre os espécimes do Lago das Ninféias.

A análise de $P$. viridis (Nitzch) Ehrenberg var. minor Cleve em Cleve (1894-1895), nome este substituído por $P$. viridiformis Krammer, mostrou que $P$. viridis (Nitzsch) Ehrenberg difere de $P$. viridiformis Krammer por ter o esterno mais estreito, a área central elíptica e a extremidade proximal da rafe termina curvada.

\section{Agradecimentos}

Os autores são profundamente gratos ao Dr. Tarciso Filgueiras pela versão para o latim da descrição original de Pinnularia brauniana var. sanctipaulensis; agradecem também ao CNPq, Conselho Nacional de Desenvolvimento Científico e Tecnológico, ACRR por bolsa de pós-graduação (mestrado) e CEMB por bolsa de produtividade (Processo $n^{\circ} 303876 / 2004-2$ ).

\section{Literatura citada}

Barcelos, E.M. 2003. Avaliação do perifíton como sensor da oligotrofização experimental em reservatório eutrófico
(Lago das Garças, São Paulo). Dissertação de Mestrado, Universidade Estadual Paulista, Rio Claro.

Bigunas, P.I.T. 2005. Diatomáceas (Ochrophyta) do rio Guaraguaçu, litoral do Paraná, Brasil. Dissertação de Mestrado, Universidade Federal do Paraná, Curitiba.

Brassac, N.M. \& Ludwig, T.A.V. 2006. Diatomáceas da Bacia do Rio Iguaçu, Paraná, Brasil: Pinnularia e Caloneis. Hoehnea 33: 127-142.

Cleve, P.T. 1894-1895. Synopsis of the naviculoid diatoms. Kungliga Svenska Vetenskapsakademiens Handlingar 26: 1-235.

Ehrenberg, C.G. 1843. Verbeitung und Einfluss des mikroskopischen Lebens in Süd- und Nord-Amerika. Kungliga der Preussischen Akademie der Wissenschaften zu Berlin 1841: 1-162.

Fermino, F.S. 2006. Avaliação sazonal dos efeitos do enriquecimento por $\mathrm{N}$ e $\mathrm{P}$ sobre o perifíton em represa tropical rasa mesotrófica (Lago das Ninféias, São Paulo). Tese de Doutorado, Universidade Estadual Paulista, Rio Claro.

Fernandes, S. 2002. Sistemas hídricos do Jardim Botânico do estado de São Paulo: uma experiência em educação para o meio ambiente. Dissertação de Mestrado, Universidade de São Paulo, São Carlos.

Ferragut, C. 2004. Respostas das algas perifíticas e planctônicas à manipulação de nutrientes $(\mathrm{N}$ e $\mathrm{P})$ em reservatório urbano (Lago do IAG, São Paulo). Tese de Doutorado, Universidade Estadual Paulista, Rio Claro.

Frenguelli, J. 1933. Diatomeas de la region de los esteros del Yberá. Anales del Museo Nacional de Historia Natural 37: 365-476.

Gaiser, E.E. \& Johansen, J. 2000. Freshwater diatoms from Carolina Bays and other isolatedt Wetlands on the Atlantic Coastal Plain of South Carolina, U.S.A., with descriptions of seven taxa new to science. Diatom Research 15: 75-130.

Germain, H. 1981. Flore des diatomées. Societé Nouvelle des Éditions Boubée, Paris.

Hasle, G.R. \& Fryxell, G.A. 1970. Diatoms: cleaning and mounting for light and electron microscopy. Transactions of the American Microscopical Society 89: 496-474.

Hendey, N. 1964. An introductory account of the smaller algae of Britisch coastal waters, 5: Bacillariophyceae (Diatoms). Fischeries Investigations Series. London, Her Majesty's Stationery Office, vol. 4(5), 317 p.

Hustedt, F. 1930. Bacillariophyta (Diatomeae). In: A. Pascher (ed.). Die Süsswasser-Flora Mitteleuropas, v. 10. Koeltz Science Publisher, Koenigstein.

Hustedt, F. 1938. Diatomeen von Java, Bali und Sumatra. Archiv für Hydrobiologie, parte 1. 
Krammer, K. 1992a. Eine Monographie der europäischen Taxa - Pinnularia. Biblioteca Diatomologica, v. 26. J. Cramer, Stuttgart.

Krammer, K. 1992b. Die Gattung Pinnularia in Bayern. Hoppea, Denkschriften der Regensburgischen Botanischen Gesellschaft 52: 5-291.

Krammer, K. 2000. The genus Pinnularia. In: H. LangeBertalot (ed.). Diatoms of Europe, v. 1. A.R.G. Gantner, Ruggell.

Krammer, K. \& Lange-Bertalot, H. 1986. Bacillariophyceae: Naviculaceae. In: H. Ettl, J. Gerloff, H. Heynig \& D. Mollenhauer. (eds.). Süßwasserflora von Mitteleuropa, v. 2, part 1. G. Fischer, Sttugart.

Lopes, M.R.M. 1999. Eventos perturbatórios que afetam a biomassa, a composição e a diversidade de espécies do fitoplâncton em um lago tropical oligotrófico raso (Lago do Instituto Astronômico e Geofísico, São Paulo, SP). Tese de Doutorado, Universidade de São Paulo, São Paulo.

Mann, D. 2001. A discussion of Caloneis and related genera. Diatom Research 17: 29-36.

Manguin, E. 1952. Bacillariophyceae. In: P. Bourrely \& E. Manguin (eds.). Algues d'eau douce de la Guadeloupe et dépendances. Société d'Edition d'Enseignement Supérieur, Paris.

Metzeltin, D. \& Lange-Bertalot, H. 1998. Tropical Diatoms of South America, 1. In: H. Lange-Bertalot (ed.). Iconographia Diatomologica, annotated diatom micrographs, v. 5. Koeltz Scientific Books, Stuttgart.

Metzeltin, D. \& Lange-Bertalot, H. 2002. Diatoms from the "Island Continent". Madagascar. In: H. LangeBertalot (ed.). Iconographia Diatomologica, annotated diatom micrographs, v. 11. Koeltz Scientific Books, Stuttgart.

Metzeltin, D. \& Lange-Bertalot, H. 2007. Tropical Diatoms of South America, 2. In: H. Lange-Bertalot (ed.). Iconographia Diatomologica, annotated diatom micrographs, v. 18. Koeltz Scientific Books, Stuttgart.

Metzeltin, D., Lange-Bertalot, H. \& García-Rodríguez, F. 2005. Diatoms of Uruguai. In: H. Lange-Bertalot (ed). Iconographia Diatomologica, annotated diatom micrographs, v. 15. Koeltz Scientific Books, Stuttgart.

Morales, E.A. \& Vis, M.L. 2007. Epilithic diatoms (Bacillariophyceae) from cloud forest and alpine streams in Bolivia, South America. Proceedings of the Academy of Natural Sciences of Philadelphia 156: 123-155.

Moura, A.N. 1997. Estrutura e produção primária da comunidade perifítica durante o processo de colonização em substrato artificial no Lago das Ninféias, São Paulo, SP: análise comparativa entre períodos chuvoso e seco. Tese de Doutorado, Universidade Estadual Paulista, Rio Claro.

Patrick, R. \& Reimer, C.W. 1966. The diatoms of United States: exclusive of Alaska and Hawaii, v. 1, n. 13. Academy of Natural Sciences, Philadelphia.

Rabenhorst, L. 1853. Die Süßwasser-Diatomaceen (Bacillarien) für Freunde der Mikroskopie. Eduard Kummer, Leipzig.

Reichardt, E. \& Jahn, R. 1995. Die Diatomeen (Bacillariophyceae) in Ehrenberg's material von Cayenne, Guayana Gallica (1843). In: H. LangeBertalot (ed.). Iconographia Diatomologica, annotated diatom micrographs, v. 1. Koeltz Scientific Books, Stuttgart.

Rocha, A.C.R. 2008. A família Pinnulariaceae (Bacillariophyceae) no estado de São Paulo: levantamento florístico. Dissertação de mestrado, Universidade Estadual Paulista, Rio Claro.

Round, F.E., Crawford, R.M. \& Mann, D.G. 1990. The diatoms: biology and morphology of the genera. Cambridge University Press, Cambridge.

Sant'Anna, C.L., Azevedo, M.T.P. \& Sormus, L. 1989. Fitoplâncton do Lago das Garças, Parque Estadual das Fontes do Ipiranga, SP, Brasil: estudo taxonômico e aspectos ecológicos. Hoehnea 16: 89-131.

Sant'Anna, C.L., Sormus, L., Tucci, A. \& Azevedo, M.T.P. 1997. Variação sazonal do fitoplâncton do Lago das Garças, São Paulo, SP, Brasil. Hoehnea 24: 67-86.

Schmidt, A. 1874-1959. Atlas der Diatomaceen-Kunde. Reisland, Leipzig.

Simonsen, R. 1987. Atlas and catalogue of the diatom types of Fredrich Hustedt, v. 3. J. Cramer, Berlin

Tucci, A. 1997. Variação temporal e espacial da estrutura da comunidade fitoplanctônica em uma lagoa eutrófica, São Paulo, SP, Brasil, em duas épocas do ano: chuva e seca. Dissertação de Mestrado, Universidade Estadual Paulista, Rio Claro.

van Heurck, H. 1880-1886. Synopsis des diatomées de Belgique. Edité par l'auteur, Anvers.

Vercellino, I.S. 2001. Sucessão da comunidade de algas perifíticas em dois reservatórios do Parque Estadual das Fontes do Ipiranga, São Paulo: influência do estado trófico e período climatológico. Dissertação de Mestrado, Universidade Estadual Paulista, Rio Claro. 